"This document is the Accepted Manuscript version of a Published Work that appeared in final form in Journal of the American Chemical Society, copyright $\odot$ American Chemical Society after peer review and technical editing by the publisher. To access the final edited and published work see [insert ACS Articles on Request author- directed link to Published Work, see http://pubs.acs.org/page/policy/articlesonrequest/index.html]."

http://pubs.acs.org/doi/abs/10.1021/jacs.5b06541

\title{
Intramolecular proton transfer boosts water oxidation catalyzed by a Ru complex
}

Roc Matheu, ${ }^{a}$ Mehmed Z. Ertem, ${ }^{\mathrm{b}}$ Jordi Benet-Buchholz, ${ }^{a}$ Eugenio Coronado, ${ }^{c}$ Victor S. Batista, ${ }^{\mathrm{d}, *}$ Xavier Sala, ${ }^{\mathrm{e}, *}$ and Antoni Llobet, ${ }^{\mathrm{a}, \mathrm{e}, *}$

${ }^{a}$ Institute of Chemical Research of Catalonia (ICIQ), Avinguda Països Catalans 16, 43007 Tarragona, Spain.

${ }^{\mathrm{b}}$ Chemistry Department, Brookhaven National Laboratory, Upton, NY 11973, USA.

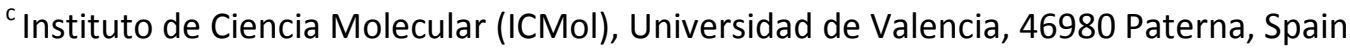

d Department of Chemistry, Yale University. P.O. Box 208107, New Haven, CT 06520-8107, USA.

e Departament de Química, Universitat Autònoma de Barcelona, Cerdanyola del Vallès, 08193 Barcelona, Spain. 


\section{Abstract}

We introduce a new family of complexes of general formula $\left[R u^{n}(t d a)(p y)_{2}\right]^{m+}(n=2, m=0,1$; $\left.\mathrm{n}=3, \mathrm{~m}=1,2^{+} ; \mathrm{n}=4, \mathrm{~m}=2,3^{2+}\right)$, with $\mathrm{tda}^{2-}=\left[2,2^{\prime}: 6^{\prime}, 2^{\prime \prime}\right.$-terpyridine]-6,6"-dicarboxylate, including complex $\left[\mathrm{Ru}^{\mathrm{IV}}(\mathrm{OH})\left(\mathrm{tda}-\kappa-\mathrm{N}^{3} \mathrm{O}\right)(\mathrm{py})_{2}\right]^{+} \mathbf{4} \mathbf{H}^{+}$which we find to be an impressive water oxidation catalyst, formed by hydroxo coordination to $3^{2+}$ under basic conditions. The complexes are synthesized, isolated and thoroughly characterized by analytical, spectroscopic (UV-Vis, NMR, EPR), computational and electrochemical techniques (CV, DPV, Coulometry), including solid state monocrystal X-ray diffraction analysis. In the oxidation state IV, the Ru center is seven coordinated and diamagnetic, whereas in oxidation state II the complex has an unbonded dangling carboxylate, so is six coordinated while still diamagnetic. With oxidation state III, the coordination number is halfway between the coordination of oxidation state II and IV. Species generated in situ have also been characterized by spectroscopic, computational and electrochemical techniques, together with the related species derived from a different degree of protonation and oxidation states. $\mathbf{4 H}^{+}$can be generated potentiometrically, or voltammetrically, from $\mathbf{3}^{2+}$ and both coexist in solution. While complex $3^{2+}$ is not catalytically active, the catalytic performance of complex $\mathbf{4 \mathbf { H } ^ { + }}$ is characterized by the foot of the wave analysis (FOWA), giving an impressive TOF record of $8,000 \mathrm{~s}^{-1}$ at $\mathrm{pH}=7.0$ and $50,000 \mathrm{~s}^{-1}$ at $\mathrm{pH}=$ 10.0. DFT calculations provide a complete description of the water oxidation catalytic cycle of $\mathbf{4 H}^{+}$manifesting the key functional role of the dangling carboxylate in lowering the activation free energies leading to $\mathrm{O}-\mathrm{O}$ bond formation. 


\section{Introduction}

Fundamental understanding of the electronic and structural factors that determine the ultimate performance of water oxidation catalysts (WOCs) is critical for the development of catalytic systems for energy conversion. ${ }^{1,2,3,4,5,6}$ Efficient functionality for fast and oxidatively rugged $^{7,8}$ performance at neutral $\mathrm{pH}$ can provide durability for sufficiently long times as necessary for practical applications. ${ }^{9,10}$ Here, we introduce and characterize a new family of Ru complexes, including compound $\left[\mathrm{Ru}^{\mathrm{IV}}(\mathrm{OH})\left(\mathrm{tda}-\kappa-\mathrm{N}^{3} \mathrm{O}\right)(\mathrm{py})_{2}\right]^{+}$with $\mathrm{tda}^{2-}=\left[2,2^{\prime}: 6^{\prime}, 2^{\prime \prime}\right.$-terpyridine $]$ 6,6"-dicarboxylate, found to be an impressive water oxidation catalyst both under neutral and alkaline conditions.

Transition metal complexes provide an excellent platform for mechanistic studies based on ligand design. ${ }^{11,12,13}$ In particular, Ru-aqua complexes with polypyridylic ligands ${ }^{14,15,16,17}$ are robust catalysts that allow for the analysis of mechanisms much more accessible than those of first row transition metals with labile ligands. ${ }^{18,19,20,21,22}$ When combined with the theoretical analysis, via density functional theory (DFT) calculations, spectroscopic and electrochemical measurements provide detailed information on the nature of reaction intermediates and activation free energies along the catalytic cycle of water oxidation. $23,24,25,26,27,28,29,30$ Strong sigma donation groups like carboxylate ligands in 2,2'-bipyridine-6,6'-dicarboxylic acid $\left(\mathrm{H}_{2} \mathrm{bda}\right.$; see Chart 1 for a drawing), together with seven coordination have allowed easy access to reactive species in high oxidation states such as $\left[\mathrm{Ru}^{\mathrm{V}}(\mathrm{O})(\mathrm{bda})(\mathrm{pic})_{2}\right]^{+}$(pic is 4-picoline) where the metal center is at formal oxidation state of $V^{31}$ Additional tuning of the activation energy barriers can result from supramolecular interactions, based on $\pi$ - $\pi$ stacking of ligands with $\pi$ extended conjugation such as isoquinoline and its derivatives favoring formation of dinuclear peroxo intermediates. ${ }^{32,33}$ Furthermore, hydrogen bonding interactions can play a significant role in the kinetics as demonstrated with strategically substituted fluro-2,2'-bpy ligands. ${ }^{34,35,36}$ Finally, the presence of an external base can also strongly influence the kinetics of water oxidation reaction by facilitating proton coupled electron transfer (PCET) and deprotonation of the incoming water molecule at the $\mathrm{O}-\mathrm{O}$ bond formation step as has been recently proposed using phosphate, borate or carboxylate as a base. Also, a direct interaction of $\mathrm{OH}^{-}$with the $\mathrm{Ru}$ high valent reactive species at high $\mathrm{pH}$ has also been shown to enhance kinetics. ${ }^{37,38}$

Using the knowledge accumulated over recent years, we have designed new Ru complexes that could potentially benefit from most of the considerations mentioned above. In particular, the new catalyst $\left[\mathrm{Ru}^{\mathrm{IV}}(\mathrm{OH})\left(\mathrm{tda}-\kappa-\mathrm{N}^{3} \mathrm{O}\right)(\mathrm{py})_{2}\right]^{+}$combines the various types of interactions responsible for redox leveling effects and exhibits an impressive catalytic performance of water oxidation with turnover frequencies (TOF) of 8,000-50,000 s-1 depending on $\mathrm{pH}$. To the best of our knowledge, these TOFs are the highest ever reported under analogous conditions. We describe the synthesis, spectroscopic, electrochemical and theoretical characterization of the series of $\mathrm{Ru}$ complexes with the pentadentate ligand $\left[2,2^{\prime}: 6^{\prime}, 2^{\prime \prime}\right.$-terpyridine]-6,6"dicarboxylic acid ( $\mathrm{H}_{2} \mathrm{tda}$; see Chart 1$)$. This ligand can potentially coordinate to a metal center, in a $\kappa-\mathrm{N}^{3} \mathrm{O}^{2}$ fashion in the equatorial zone. The auxiliary axial positons are coordinated by pyridine ligands that are generally not directly involved in the electron transfer and/or proton transfer, or in the O-O bond formation. 


\section{Results and Discussion}

\subsection{Synthesis and solid state structure}

The synthesis of the Ru complexes described in this work is summarized in Scheme 1. Reaction of $\left[\mathrm{Ru}^{\mathrm{II}} \mathrm{Cl}_{2}(\mathrm{dmso})_{4}\right]$ with $\mathrm{H}_{2} \mathrm{tda}^{39}$ in the presence of $\mathrm{NEt}_{3}$ as a base at reflux with $\mathrm{MeOH}$, followed by addition of pyridine and further reflux in a mixture of water and pyridine produces complex $\left[\mathrm{Ru}^{\prime \prime}\left(\mathrm{tda}-\kappa-\mathrm{N}^{3} \mathrm{O}\right)(\mathrm{py})_{2}\right], 1$, in $50 \%$ isolated yield. Treatment of the latter with one equivalent of $\mathrm{Ce}(\mathrm{IV})$ as an oxidant generates the $\left[\mathrm{Ru} \mathrm{u}^{\prime \prime \prime}\left(\mathrm{tda}-\kappa-\mathrm{N}^{3} \mathrm{O}^{2}\right)(\mathrm{py})_{2}\right]\left(\mathrm{PF}_{6}\right), \mathbf{2}\left(\mathrm{PF}_{6}\right)$, complex. Subsequent addition of one more equivalent of $\mathrm{Ce}(\mathrm{IV})$ to $\mathbf{2}^{+}$generates [ $\mathrm{Ru}^{\mathrm{IV}}$ (tda-k$\left.\left.\mathrm{N}^{3} \mathrm{O}^{2}\right)(\mathrm{py})_{2}\right]\left(\mathrm{PF}_{6}\right)_{2}, 3\left(\mathrm{PF}_{6}\right)_{2}$, in $39 \%$ and $32 \%$ isolated yield, respectively. All of these new complexes are characterized analytically and spectroscopically by UV-vis, EPR and $1 D$ and $2 D$ NMR in solution as presented and discussed in the following section. In addition, monocrystal $X$-ray diffraction analysis has been carried out to characterize the complexes in the solid state. Ortep drawings of $\mathbf{1}$ and those of the cationic moieties of $\mathbf{2}^{+}$and $\mathbf{3}^{2+}$ are presented in Figure 1.

Complex $\mathbf{1}$ displays the typical distorted octahedral geometry around the Ru center as expected for low spin $d^{6} \mathrm{Ru}(I I) .{ }^{29,32,40,41}$ The pyridine monodentate ligands occupy the axial positions whereas $\mathrm{tda}^{2-}$ binds as an equatorial ligand. With Ru in oxidation state $\mathrm{II}, \mathrm{tda}^{2-}$ binds in a tetradentate $\kappa-\mathrm{N}^{3} \mathrm{O}$ fashion with a non-bonding dangling carboxylate as shown in Figure 1. In oxidation state III, two different structural units are found in the unit cell of complex $\left[\mathrm{Ru}^{\prime \prime \prime}\left(\mathrm{tda}-\kappa-\mathrm{N}^{3} \mathrm{O}^{2}\right)(\mathrm{py})_{2}\right]^{+}, \mathbf{2}^{+}$. One of these structures has the tda ${ }^{2-}$ ligand bound in a $\kappa-\mathrm{N}^{2} \mathrm{O}^{2}$ mode with the central pyridyl of this ligand formally non-bonded although at "contact" distance (Ru-N distance $=2.38 \AA$ A $)$. The other Ru(III) structure also has tda ${ }^{2-}$ as a tetradentate ligand although bound in a $\kappa-\mathrm{N}^{3} \mathrm{O}$ mode, with the two carboxylates weakly bonded with long Ru-O distances of $2.33 \AA$ and $2.23 \AA$, respectively (typical $\mathrm{Ru}(\mathrm{III})-\mathrm{O}_{\text {carboxylate }}$ bonds are in the 1.9$2.1 \AA$ range). ${ }^{31,42}$ Given the fact that the five $\mathrm{N}^{3} \mathrm{O}^{2}$ atoms are all partially involved in bonding at $100 \mathrm{~K}$, we label the complex "tda- $\mathrm{K}-\mathrm{N}^{3} \mathrm{O}^{2 \text { " }}$ although the 18-electron rule is satisfied when only four of the atoms are effectively bound to $\mathrm{Ru}(\mathrm{III}) .{ }^{43}$ As the axial pyridines are always fully bound to $\mathrm{Ru}$, we expect that the Ru-N and Ru-O bonds are simultaneously made and broken very quickly at room temperature, as represented by the dashed lines in Scheme 1. Density functional theory (DFT) calculations based on the M06- $\mathrm{L}^{44}$ and M11- $\mathrm{L}^{45}$ functionals (see Computational Methods in SI for details) provide optimized structures for the Ru-tda complexes at different oxidation states (Figure S25 in the SI). The comparison of the calculated and $\mathrm{X}$-ray bond lengths indicate good agreement (Table $\mathrm{S} 2$ in the $\mathrm{SI}$ ). For Ru" oxidation state,

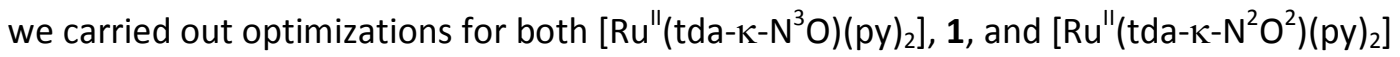
conformers and found 1 to be more stable by $5.6 \mathrm{kcal} / \mathrm{mol}$ in line with the experimental observations. For oxidation states III and IV, the DFT calculations favored one conformer, namely $\left[\mathrm{Ru}^{\prime \prime \prime}\left(\mathrm{tda}-\kappa-\mathrm{N}^{2} \mathrm{O}^{2}\right)(\mathrm{py})_{2}\right]^{+}$and $\left[\mathrm{Ru}^{\mathrm{IV}}\left(\mathrm{tda}-\kappa-\mathrm{N}^{3} \mathrm{O}^{2}\right)(\mathrm{py})_{2}\right]^{2+}, \mathbf{3}^{2+}$, which will be discussed in the following sections. 


\subsection{Spectroscopic Characterization based on NMR, EPR and UV-vis.}

Figure 2 shows the ${ }^{1} \mathrm{H}$ NMR spectra of complexes $1, \mathbf{2}^{+}$and $\mathbf{3}^{2+}$ in $\mathrm{pD}=7.0$ solutions of phosphate buffer. As expected, the high-field octahedral $d^{6} \mathrm{Ru}(\mathrm{II})$ complex $\mathbf{1}$ is diamagnetic and all resonances could be easily assigned based on integrations, multiplicity and the combination of 1D and 2D NMR (see SI for a complete set of spectra). For 1, the resonances due to the tda ${ }^{2-}$ ligand are symmetric indicating a fast dynamic behavior at room temperature. Further, the room temperature $2 \mathrm{D}^{15} \mathrm{~N}-{ }^{1} \mathrm{H}$ HMBC (see figure S6) of 1 shows that all of the $\mathrm{N}$ atoms of $\mathrm{tda}^{2-}$ are bonded to the metal center. Therefore, the dynamical ligand exchange behavior is limited to the carboxylate sites, as indicated by equation 1 .
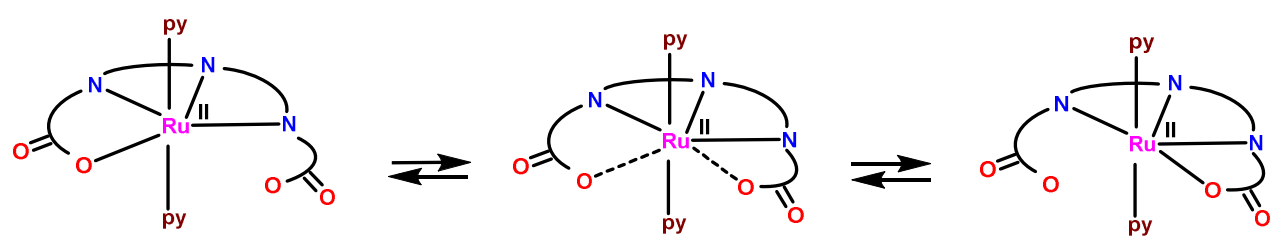

Complex $\mathbf{3}^{2+}$ is also diamagnetic, as expected for a low spin $d^{4} \mathrm{Ru}(\mathrm{IV})$ ion with a (dxz, $d y z)^{4}$ electronic configuration and pentagonal bipyramidal geometry. When compared to the ${ }^{1} \mathrm{H}$ NMR spectra of the Ru(II) complexes, the resonances of the Ru(IV) complex are shifted to a lower field in accordance with the higher oxidation state of the Ru center. In contrast, complex $\mathbf{2}^{+}$is paramagnetic as expected for an octahedral low spin $\mathrm{d}^{5}$ ion with an unpaired electron. As can be observed in Figure 2, all resonances are broadened and highly shifted with regard to those of the Ru(II) analogue, partly due to the paramagnetic effect of the unpaired electron over the nuclear spin. On the other hand, complex $\mathbf{2}^{+}$shows an axial EPR spectrum with $\mathrm{g}_{/ /}=$ 2.10 and $g_{\perp}=2.0$, which is in agreement with the presence of two py ligands occupying the axial positions of the octahedron (Figure 2). Both $\mathrm{Ru}(\mathrm{II})$ and $\mathrm{Ru}(\mathrm{IV})$ are EPR silent as expected for complexes with no unpaired electrons. The EPR experiments were carried out at $4 \mathrm{~K}$ on frozen solutions by using a X-band spectrometer.

The UV-vis spectra of complexes $1, \mathbf{2}^{+}$and $\mathbf{3}^{2+}$, dissolved in $0.1 \mathrm{M}$ triflic acid aqueous solutions $(\mathrm{pH}=1.0)$, are shown in Figure 3 . Analogous spectra could be obtained by spectrophotometric redox titration of 1 with $\mathrm{Ce}(\mathrm{IV})$ exhibiting isosbestic points as displayed in the SI. Typical Ru-bpy MLCT bands are observed in the 420-620 nm range for 1, whereas a single transition at $420 \mathrm{~nm}$ is observed in that range of the spectrum for Ru(III), which is essentially featureless for Ru(IV).

It is important to mention that complex $\mathbf{3}^{2+}$ is very stable at $\mathrm{pH}=1.0$, as evidenced by the UV-vis spectrum which remains unchanged for several days. However, at $\mathrm{pH}=7.0$ the spectrum decays slowly (in about $3 \mathrm{~h}$ ) back and cleanly to oxidation state (III) to form $\mathbf{2}^{+}$ through isosbestic points as shown in Figure 3 (right). The spectral decay is associated with slow oxidation of water by $3^{2+}$, since at neutral $\mathrm{pH}$ the redox couple IV/III is above the thermodynamic potential for water oxidation, consistent with previous observations for related Ru complexes. ${ }^{46,47}$ 


\subsection{Stability of high oxidation states and formation of Ru-aqua species.}

We have analyzed the redox properties of the complex $\left[R u^{\prime \prime}\left(t d a-N^{3} O\right)(p y)_{2}\right], \mathbf{1}$, in aqueous solutions at different $\mathrm{pH}$ by the electrochemical measurements based on cyclic voltammetry (CV), differential pulse voltammetry (DPV) and coulometry. The CV and DPV experiments were carried out using glassy carbon disk working electrodes and a platinum wire as auxiliary, and mercury sulfate as reference electrode (MSE) and reported vs. NHE.

Two chemically reversible and electrochemically quasireversible waves are observed at $E_{1 / 2}=0.52 \mathrm{~V}(\Delta E=60 \mathrm{mV})$ and $1.10 \mathrm{~V}(60 \mathrm{mV})$ as detected by $\mathrm{CV}$ at $\mathrm{pH}=7.0$ and shown in Figure 4 left. Both waves are $\mathrm{pH}$-independent in the $\mathrm{pH}=2-10$ range and are assigned to two consecutive metal based one-electron oxidation processes, namely $\mathrm{Ru}$ (II) $->\mathrm{Ru}$ (III) $>\mathrm{Ru}$ (IV). It is interesting to analyze the scan rate dependence $(v=20,10$ and $7.5 \mathrm{mV} / \mathrm{s})$ in the $1.35-1.45 \mathrm{~V}$ zone. As can be noticed in Figure 4, the current intensity at $1.4 \mathrm{~V}$ increases as the scan rate decreases, relative to the current intensity of the second anodic wave at $1.10 \mathrm{~V}$ suggesting the presence of a new electroactive process that is favored at longer time scales. A similar phenomenon can be detected by DPV under analogous conditions while changing the $\mathrm{pH}$ (Figure 4, right). As the pH increases from 6.5 all the way to 10.0, the intensity of the current increases dramatically in the 1.35-1.45 $\mathrm{V}$ range. This phenomenon is attributed to the coordination of the hydroxide anion to the metal center, followed by a one electron oxidation as indicated in equations 2 and 3 . This assumption is further supported by electrochemical and spectroscopic evidence as will be described here on.

$$
\underset{\mathbf{3}^{2+}}{\left[\mathrm{Ru}^{\mathrm{IV}}\left(\mathrm{tda}-\kappa-\mathrm{N}^{3} \mathrm{O}^{2}\right)(\mathrm{py})_{2}\right]^{2+}}+\underset{\mathrm{OH}^{-}}{-\rightarrow} \quad\left[\begin{array}{c}
\left.\mathrm{Ru}^{\mathrm{IV}}(\mathrm{OH})\left(\mathrm{tda}-\kappa-\mathrm{N}^{3} \mathrm{O}\right)(\mathrm{py})_{2}\right]^{+} \\
\mathbf{4} \mathrm{H}^{+}
\end{array}\right.
$$

$\left[R u^{\mathrm{IV}}(\mathrm{OH})\left(\mathrm{tda}-\kappa-\mathrm{N}^{3} \mathrm{O}\right)(\mathrm{py})_{2}\right]^{+}-\mathrm{e}^{-}-\mathrm{H}^{+}->$
$\mathbf{4 \mathbf { H } ^ { + }}$

Complex $4 \mathrm{H}^{+}$has a $\mathrm{pK}_{\mathrm{a}}=5.5$, as shown in the Pourbaix diagram discussed below. Therefore, at $\mathrm{pH}>5.5, \mathbf{4} \mathrm{H}^{+}$is deprotonated to form $\left[\mathrm{Ru}^{\mathrm{IV}}(\mathrm{O})\left(\mathrm{tda}-\kappa-\mathrm{N}^{3} \mathrm{O}\right)(\mathrm{py})_{2}\right]$, 4. Further oxidation of $\mathbf{4 H}^{+}$or $\mathbf{4}$ (depending on the $\mathrm{pH}$ ) forms the $\mathrm{Ru}(\mathrm{V})$ species that is a highly reactive water oxidation catalyst that can be detected in very small concentrations. These electrochemical experiments clearly show that two set of species coexist at high $\mathrm{pH}$, including species with hydroxo or oxo terminal ligands $\left(\mathbf{4 H}^{+}, \mathbf{5}^{+}, \mathbf{6}\right)$, named from now on "Ru-aqua", and others not containing these ligands $\left(\mathbf{1}, \mathbf{2}^{+}, \mathbf{3}^{2+}\right)$, called from now "Ru non-aqua" species, as shown in Scheme 1. The redox properties of the "Ru-aqua" species are summarized in Scheme 2 and their spectroscopic and catalytic properties are discussed below.

Complex $\mathbf{4}$ can also be generated potentiostatically and monitored voltammetrically in a $\mathrm{pH}=7.0$ phosphate buffer solution using a bipotentiostat in a two compartment cell as shown in Figure 5 (see $\mathrm{SI}$ for further details). For this experiment a glassy carbon disk is used as 
a working electrode for the CV experiments whereas a Pt grid is used as working electrode to potentiostatically generate 4 at an applied potential of $1.25 \mathrm{~V}$ for 10 hours. As can be seen in Figure 5 , only $1, \mathbf{2}^{+}$and $\mathbf{3}^{2+}$ are initially present in solution as shown by the red dashed line. As time elapses ( 333 scans at a scan rate of $20 \mathrm{mV} / \mathrm{s}$ ), the waves due to first and second oxidation of 1 decrease in intensity and new waves are formed at around 0.7 and $0.9 \mathrm{~V}$. In addition, a large electrocatalytic wave develops at $1.30 \mathrm{~V}$. Judging by the relative integrated charge, obtained under the cathodic wave for the IV/III couple $\left(\mathbf{3}^{2+}+1 \mathrm{e}^{-}-\mathbf{2}^{+}\right)$versus the new cathodic wave at $0.7 \mathrm{~V}$, the ratio of "Ru non-aqua" versus the "Ru-aqua" complexes is about 2:1. The generation of the "Ru-aqua" species was found to be much faster when the initial non-aqua complex 1 was dissolved at higher pH in agreement with the DPV shown in Figure 4 (right).

The redox properties of "Ru-aqua" species were analyzed based on CV experiments and are shown in Figure 5 (right) at $\mathrm{pH}=8.2$. A summary of the redox processes of "Ru-aqua" complexes is given in Scheme 2 and can be easily rationalized following the reduction process starting form the most oxidized seven coordinated species $\left[\mathrm{Ru}^{\mathrm{V}}(\mathrm{O})\left(\mathrm{tda}-\kappa-\mathrm{N}^{3} \mathrm{O}\right)(\mathrm{py})_{2}\right]^{+}, \mathbf{5}^{+}$, and keeping in mind that the geometry of the ligand $\mathrm{tda}^{2-}$ together with the different electronic nature of $\mathrm{Ru}(\mathrm{II})$ and $\mathrm{Ru}(\mathrm{III})$ foster linkage isomerization processes. ${ }^{48,49,50}$ Complex $\mathbf{5}^{+}$is responsible for the catalytic water oxidation reaction that will be described in the next section, and its formal V/IV redox couple at this $\mathrm{pH}$ is obtained by DPV $\left(E_{1 / 2}{ }^{4}=1.43 \mathrm{~V}\right.$; Figure S20). The one electron reduction of $5^{+}$(Scheme 2$)$, generates $\left[\mathrm{Ru}^{\mathrm{IV}}(\mathrm{O})\left(\mathrm{tda}-\kappa-\mathrm{N}^{3} \mathrm{O}\right)(\mathrm{py})_{2}\right], 4$, that in turn can be further reduced by a one electron process $\left(E_{1 / 2}{ }^{3}=0.87 \mathrm{~V}\right)$ to generate [Ru' $(\mathrm{OH})(\mathrm{tda}-\kappa-$ $\left.\left.\mathrm{N}^{3} \mathrm{O}\right)(\mathrm{py})_{2}\right], 6$. The latter has Ru-O and Ru-N bonds that form and break very quickly since $\mathrm{Ru}(\mathrm{III})$ is now six coordinated. Subsequent reduction to $\mathrm{Ru}(\mathrm{II})\left(E_{1 / 2}{ }^{1}=0.70 \mathrm{~V}\right)$ generates a $\mathrm{Ru}(\mathrm{II})$-aqua complex, $\left[\mathrm{Ru}^{\prime \prime}\left(\mathrm{H}_{2} \mathrm{O}\right)\left(\right.\right.$ tda- $\left.\left.\kappa-\mathrm{N}^{3} \mathrm{O}\right)(\mathrm{py})_{2}\right], 7$, that is highly unstable and isomerizes to form $\left[\mathrm{Ru}^{\prime \prime}\left(\mathrm{H}_{2} \mathrm{O}\right)\left(\right.\right.$ tda-K- $\left.\left.\mathrm{N}^{3}\right)(\mathrm{py})_{2}\right], 8$, a process denoted by $\mathrm{K}^{\prime \prime}$ in Scheme 2. Oxidation of the latter to $\mathrm{Ru}(\mathrm{III}),\left(E_{1 / 2}^{2}=0.77 \mathrm{~V}\right)$, forms a very unstable species, [Ru' $\left.(\mathrm{OH})\left(\mathrm{tda}-\kappa-\mathrm{N}^{3}\right)(\mathrm{py})_{2}\right]$, 9, that quickly isomerizes to form $\mathbf{6}\left(\mathrm{K}^{\mathrm{III}}\right.$ in Scheme 2 ) closing the thermodynamic square cycle. This square mechanism is further corroborated by DPV in the oxidative and reductive scans, shown in Figure 5 (top right).

We studied the redox behavior of the "Ru-aqua" species derived from complex 1 , as a function of $\mathrm{pH}$, to generate the Pourbaix diagram that defines the zones of equilibrium between species with different oxidation and protonation states (Figure 6). For comparison, the $\mathrm{pH}$-independent redox potentials of the "Ru non-aqua" species are included (solid blue line) together with the thermodynamic potential of the $4 \mathrm{e}^{-}$water oxidation to dioxygen (green broken line). Several interesting features of the Pourbaix diagram are worth mentioning: i) the change in slope for the $\mathrm{Ru}(\mathrm{V}) / \mathrm{Ru}(\mathrm{IV})$ redox couple $\left(E_{1 / 2}{ }^{4}\right)$ gives a $\mathrm{pK}_{\mathrm{a}}$ of 5.5 for $\mathrm{Ru}(\mathrm{IV})-\mathrm{OH}$ to $\mathrm{Ru}(\mathrm{IV})-\mathrm{O}$ species; ii) above $\mathrm{pH}=4.0$ the redox potential for the couple $" \mathbf{3}^{2+}+1 \mathrm{e}^{-}->\mathbf{2}^{+ \text {“ }}(\mathrm{Ru}(\mathrm{IV})+$ $1 \mathrm{e}->\mathrm{Ru}(\mathrm{III})$, in blue in the diagram), is higher than the potential of the four electron oxidation of water to dioxygen. Thus, it is in agreement with the stability of complex $3^{2+}$ at $\mathrm{pH}=1.0$ and the decay to lower oxidation states at higher $\mathrm{pH}$ due to water oxidation; ${ }^{46}$ iii) for the "Ru-aqua" complex system, a plot of the III/II couple associated with $E_{1 / 2}{ }^{1}$ is presented. The $E_{1 / 2}{ }^{2}$ potential is roughly over $100 \mathrm{mV}$ from that of $E_{1 / 2}{ }^{1}$ and is not shown; iv) the label Ru-OH refers to the complex $\left[\mathrm{Ru}^{\prime \prime}\left(\mathrm{H}_{2} \mathrm{O}\right)\left(\mathrm{Htda}-\kappa-\mathrm{N}^{3} \mathrm{O}\right)(\mathrm{py})_{2}\right], 7$, with one of the dangling carboxylate ligands 
protonated, $\mathbf{7} \mathbf{H}^{+}$. Again here as in oxidation state $\mathrm{III}$, the $\mathrm{tda}{ }^{2-}$ ligand only provides 3 coordination positions.

Finally, addition of a chemical reducing agent like ascorbic acid to the solution containing a 2:1 ratio of "Ru non-aqua":"Ru-aqua" species generates a solution with $\mathbf{1}$ as the only present species as demonstrated by ${ }^{1} \mathrm{H}$ NMR spectroscopy (see SI for details). These results suggest a slow equilibrium between $\mathbf{1}$ and $\mathbf{8}$ thermodynamically favored towards the former.

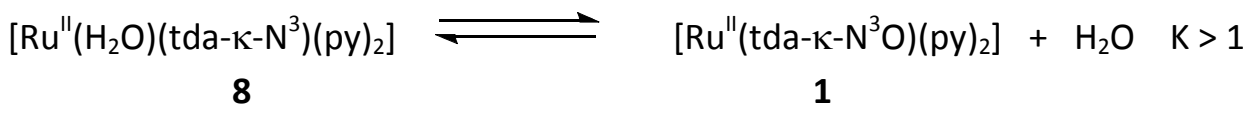

In addition the full recovery of $\mathbf{1}$, with no other species in solution, highlights the ruggedness of the system with no deactivation pathways detected. (see Figure S21 in the ESI)

\subsection{Spectroscopic characterization of "Ru-aqua" species based on NMR and EPR spectroscopy.}

The "Ru-aqua" species were characterized by NMR and EPR spectroscopy, as shown in Figure 7. A solution with $5 \mathrm{mM:1} \mathrm{mM}$ "Ru non-aqua":" Ru-aqua" species was generated potentiostatically by applying $1.25 \mathrm{~V}$ for $1.5 \mathrm{~h}$ to a $7.0 \mathrm{mM}$ solution of 1 in a $\mathrm{D}_{2} \mathrm{O}$ phosphate buffer at $\mathrm{pH}=10.5$. After the bulk electrolysis, the final $\mathrm{pH}$ is reduced to 7 . The solution was then exposed to additional bulk electrolysis at several applied potentials to generate species with different degree of oxidation and protonation. The NMR spectra were recorded after 7 minutes of sample collection. For EPR analysis, the samples were frozen after $30 \mathrm{~s}$ and measured as frozen solutions at $4 \mathrm{~K}$. Figure 7 (center) includes a $\mathrm{CV}$ of the solution where the applied potential is indicated with vertical arrows as a guiding reference. For comparison, Figure 7 also includes the NMR and EPR spectra of $\left[R u^{\prime \prime \prime}\left(\text { tda- }-\mathrm{N}^{3} \mathrm{O}^{2}\right)(\mathrm{py})_{2}\right]^{+}, \mathbf{2}^{+}$, (black line).

The red spectra is obtained at applied potential $E_{\text {app }}=1.25 \mathrm{~V}$ until the current flow was below $5 \%$ of the initial current (approximately 15 minutes). At this potential, two diamagnetic species were generated, the $\left[R u^{\mathrm{IV}}\left(\mathrm{tda}-\kappa-\mathrm{N}^{3} \mathrm{O}^{2}\right)(\mathrm{py})_{2}\right]^{2+}, \mathbf{3}^{2+}$ and $\left[R u^{\mathrm{IV}}(\mathrm{O})\left(\mathrm{tda}-\kappa-\mathrm{N}^{3} \mathrm{O}\right)(\mathrm{py})_{2}\right], 4$. The latter decays to $\left[\mathrm{Ru}^{\prime \prime \prime}(\mathrm{HO})\left(\mathrm{tda}-\kappa-\mathrm{N}^{3} \mathrm{O}\right)(\mathrm{py})_{2}\right], 6$, whose EPR spectrum is shown in red. This spectrum shows a rhombic signal with $g_{1}=2.12, g_{2}=2.08$ and $g_{3}=1.85$. The larger spin anisotropy found in $\mathbf{6}$ compared with that found in $\mathbf{2}$ is in agreement with the larger distortion of the octahedral Ru' site upon $\mathrm{OH}^{-}$coordination. The instability of $\mathrm{Ru}(\mathrm{IV})=\mathrm{O}$ species, $\left[\mathrm{Ru}^{\mathrm{IV}}(\mathrm{O})\left(\right.\right.$ tda- $\left.\left.\mathrm{K}-\mathrm{N}^{3} \mathrm{O}\right)(\mathrm{py})_{2}\right], 4$, decaying to $\mathrm{Ru}(\mathrm{III})$ is unlikely due to direct water oxidation by this species since the oxidation potential of $R u(I V)$ is not sufficiently high to drive that reaction. However, upon disproportionation, it can generate $\mathrm{Ru}(\mathrm{V})$ and $\mathrm{Ru}(\mathrm{III})$. The $\mathrm{Ru}(\mathrm{V})$ species in $\left[\mathrm{Ru}^{\mathrm{V}}(\mathrm{O})\left(\text { tda-k- } \mathrm{N}^{3} \mathrm{O}\right)(\mathrm{py})_{2}\right]^{+}, 5^{+}$, is a very powerful oxidant that can oxidize $\mathrm{H}_{2} \mathrm{O}$ to $\mathrm{O}_{2}$ very quickly, as will be shown in the next section, and thus is the driving force for the disproportionation. A similar mechanism was proposed recently for related mononuclear complexes. ${ }^{46,51}$ 
Furthermore, such a mechanism based on disproportionation of $\mathbf{4}$ is consistent with the lack of a returning wave for the IV/III redox couple as shown in the CV in Figure 5 (right).

The blue spectra is obtained with $E_{\text {app }}=0.95 \mathrm{~V}$ until reaching $5 \%$ of the initial current flow. The reduction generates $\left[R u^{\prime \prime \prime}\left(t d a-\kappa-N^{3} \mathrm{O}^{2}\right)(p y)_{2}\right]^{+}, \mathbf{2}^{+}$and the diamagnetic complex $\left[R u^{I V}(O)\left(\right.\right.$ tda- $\left.\left.\kappa-N^{3} O\right)(p y)_{2}\right], 4$, that decays to $\left[R u^{\prime \prime \prime}(H O)\left(t d a-\kappa-N^{3} O\right)(p y)_{2}\right]$, 6. In the NMR, the $\mathrm{Ru}(\mathrm{III})$ species $\mathbf{2}^{+}$is identified by intense resonances at 12.0 and $13.2 \mathrm{ppm}$. New resonances at 9.5 and $20.2 \mathrm{ppm}$ are assigned to $\mathbf{6}$. The EPR also shows a mixture of the spectra of $\mathbf{2}^{+}$and $\mathbf{6}$. The green spectra is obtained with $E_{\text {app }}=0.75 \mathrm{~V}$ and shows that the predominant species is $\mathbf{2}^{+}$ with a small amount of 6 . Finally, at $E_{\text {app }}=0.25 \mathrm{~V}$, all species are diamagnetic and no EPR resonances are obtained or NMR in the $11-21 \mathrm{ppm}$ range, indicating formation of 1 . This is again fully consistent with the chemical reduction carried out with ascorbic acid where the only species present was $\mathbf{1}$ as described in the previous section.

\subsection{Catalytic performance of the $\mathrm{Ru}-\mathrm{OH}_{2}$ complex and proposed mechanism based on DFT calculations}

Figure 8 shows the $\mathrm{CV}$ of a solution of $0.30 \mathrm{mM}\left[\mathrm{Ru}^{\mathrm{IV}}\left(\mathrm{tda}-\kappa-\mathrm{N}^{3} \mathrm{O}^{2}\right)(\mathrm{py})_{2}\right]^{2+}, 3^{2+}$ and $0.15 \mathrm{mM}$ $\left[\mathrm{Ru}^{\mathrm{IV}}(\mathrm{O})\left(\mathrm{tda}-\kappa-\mathrm{N}^{3} \mathrm{O}\right)(\mathrm{py})_{2}\right], 4$ at $\mathrm{pH}=7.0$. It is impressive to see the large electrocatalytic wave of roughly $10 \mathrm{~mA} / \mathrm{cm}^{2}$, in the 1.3-1.4 $\mathrm{V}$ range considering the small amount of the precursor species 4 present in solution that have a reductive III/II wave with a peak intensity of approximately $25 \mu \mathrm{A} / \mathrm{cm}^{2}$. This electrocatalytic wave is due to one electron oxidation of 4 and formation of the highly active species $\left[\mathrm{Ru}^{\mathrm{V}}(\mathrm{O})\left(\mathrm{tda}-\kappa-\mathrm{N}^{3} \mathrm{O}\right)(\mathrm{py})_{2}\right]^{+}, \mathbf{5}^{+}\left(E_{1 / 2}{ }^{4}=1.43 \mathrm{~V}\right)$. To quantitatively characterize the kinetics of the water oxidation catalysis, a foot of the wave analysis (FOWA) was carried out following the procedures proposed by Saveant et al. ${ }^{52,53,54} \mathrm{~A}$ plot of i/ip vs. $1 /\left(1+e\left(F\left(E^{0}-E\right) / R T\right)\right)$ (see Figure 8 ) gives an impressive scan rate-independent TOF $_{\max }$ of 8,000 cycles per second, which is the highest ever reported at neutral pH. It is actually one order of magnitude higher than the best one reported so far at $\mathrm{pH} 1.0$, based on Ru-bda type of complexes (see Chart 1). ${ }^{32,33}$ Further, at pH 7.0, the complex [Ru(bda)(pic) $\left.{ }_{2}\right]$ under exactly the same conditions as $\mathbf{3}^{+}$is about 3-4 orders of magnitude slower (see $\mathrm{SI}$ ), assuming a first order behavior of the catalyst at $\mathrm{pH}=7.0$ as has been recently proposed.$^{38} \mathrm{In}$ addition, the performance of 4 was evaluated at $\mathrm{pH}=8.0$ and 10.0, giving impressive TOFs of $25,000 \mathrm{~s}^{-1}$ and $50,000 \mathrm{~s}^{-1}$ respectively, indicating a significant rate enhancement as the $\mathrm{pH}$ increases. Finally, bulk electrolysis experiments using glassy carbon rods $\left(S=8.2 \mathrm{~cm}^{2}\right)$ as working electrodes further confirm $\mathrm{O}_{2}$ evolution with Faradaic efficiency around $92 \%$. (See Figure S22). To calculate the turnover number (TON) we used the methodology also develop by Saveant et al. ${ }^{52}$ that takes into account only the amount of catalyst that is surrounding the electrode. This gives a TON in the range of 27 million for one hour electrolysis (See the supporting information for further details).

The catalytic cycle was also studied via DFT calculations. We started with the Ru-aqua complex $\left[\mathrm{Ru}^{\prime \prime}\left(\mathrm{H}_{2} \mathrm{O}\right)\left(\right.\right.$ tda- $\left.\left.\kappa-\mathrm{N}^{3}\right)(\mathrm{py})_{2}\right], 7$, (Scheme 3). From 7, a PCET results in the formation of 6, followed by another PCET step to generate 4 . Further oxidation forms the seven coordinate complex $\mathbf{5}^{+}$(Figure 9, ) with a calculated potential of $1.32 \mathrm{~V}$ in very good agreement with the 
onset of the electrocatalytic wave in the $1.3-1.4 \mathrm{~V}$ range. It is worth noting that for complex $5^{+}$we found the $\kappa-\mathrm{N}^{3} \mathrm{O}$ conformer to be more stable than the $\kappa-\mathrm{N}^{3}$ conformer by $13.6 \mathrm{kcal} / \mathrm{mol}$ showing the enhanced stability of the seven coordination mode due to the $\mathrm{tda}^{2-}$ ligand framework. Next, we considered the O-O bond formation step and located a transition state (TS) structure which features a water nucleophilic attack (WNA) to the oxyl radical Ru ${ }^{\text {IV }}-0$ (formally $a \mathrm{Ru}^{\mathrm{V}}=\mathrm{O}$ unit), with concomitant proton transfer to the dangling carboxylate group of the $\mathrm{tda}^{2-}$ ligand (Figure 9). The calculated free energy of activation $\left(\Delta G^{\ddagger}\right)$ is $19.5 \mathrm{kcal} / \mathrm{mol}$ and $16.8 \mathrm{kcal} / \mathrm{mol}$ respectively at M11-L and M06-L level of theories. The calculated activation free energies are significantly lower than those calculated for other mononuclear ruthenium catalysts at same level of theory ${ }^{27,55,56}$ due to the intramolecular proton transfer to the dangling carboxylate, next to the oxyl radical. While previous examples have shown this effect, intermolecularly increasing rates by a 2 or 3 fold, ${ }^{37,38}$ we find that the intramolecular proton transfer has a much more dramatic effect leading to an extraordinary increase of the overall kinetics. The resulting product of the WNA step is $\left[\mathrm{Ru}^{\prime \prime \prime \prime}(\mathrm{OOH})\left(\mathrm{Htda}-\kappa-\mathrm{N}^{2} \mathrm{O}^{1}\right)(\mathrm{py})_{2}\right]^{+}(\Delta G=3.5$ $\mathrm{kcal} / \mathrm{mol})$ which could undergo a PCET step $(E=0.66 \mathrm{~V})$ to generate $\left[\mathrm{Ru}^{\mathrm{IV}}(\mathrm{OO})(\mathrm{Htda}-\kappa\right.$ $\left.\left.\mathrm{N}^{2} \mathrm{O}^{1}\right)(\mathrm{py})_{2}\right]^{+}$(See Figure 9 and structures in blue in Scheme 3). In the final step of the mechanism, $\mathrm{O}_{2}$ evolution with concomitant loss of proton and addition of $\mathrm{H}_{2} \mathrm{O}(\Delta G=-3.5$ $\mathrm{kcal} / \mathrm{mol}$ ) regenerates the initial $\left[\mathrm{Ru}\right.$ " $\left.\left(\mathrm{tda}-\mathrm{K}-\mathrm{N}^{3}\right)(\mathrm{py})_{2}\left(\mathrm{OH}_{2}\right)\right]$ species and completes the catalytic cycle.

It is interesting to compare the catalytic rates of water oxidation catalyzed by the related complex $\left[\mathrm{Ru}(\mathrm{bda})(\mathrm{pic})_{2}\right]$, analogous to 4 but without the dangling carboxylate. $\mathrm{At} \mathrm{pH}=$ 7.0, a k $\mathrm{k}_{\text {obs }}=6 \mathrm{~s}^{-1}$ has been reported ${ }^{38}$ and at $\mathrm{pH}=12.2$ the $\mathrm{k}_{\mathrm{obs}}$ increases up to $14000 \mathrm{~s}^{-1}$. It is impressive to see that for complex 4 with the capacity to undergo proton transfer intramolecularly boosts the rate up to $8,000 \mathrm{~s}^{-1}$ at $\mathrm{pH}=7.0$ and $50,000 \mathrm{~s}^{-1}$ at $\mathrm{pH}=10$. Thus, an increase of more than three orders of magnitude in rate is achieved at $\mathrm{pH}=7.0$ with regard to the current benchmark catalyst. The increase of catalytic rate based on intramolecular proton transfer is reminiscent of other catalytic systems that also exploit acid-base functional groups in the second coordination sphere of the metal center, including Ni complexes introduced by Dubois et al, ${ }^{57}$ where the ligands have pendant amines that function as proton relays.

\section{Conclusions}

We have introduced a new family of complexes where the pentadentate tda ${ }^{2-}$ coordinates to Ru metal center as an equatorial ligand while monodenate pyridine ligands coordinate to the axial positions. The strong sigma donation of the carboxylate moieties of $\mathrm{tda}^{2-}$, stabilizes a seven coordinate $\mathrm{Ru}(\mathrm{IV})$ complex, $\left[\mathrm{Ru}{ }^{\mathrm{IV}}\left(\mathrm{tda}-\kappa-\mathrm{N}^{3} \mathrm{O}^{2}\right)(\mathrm{py})_{2}\right]^{2+}, 3^{2+}$, both in organic solvents as well as in water, or in acidic aqueous solutions. In basic solutions, hydroxide displaces one of the carboxylate groups, forming $\left[\mathrm{Ru}^{\mathrm{IV}}(\mathrm{OH})\left(\mathrm{tda}-\kappa-\mathrm{N}^{3} \mathrm{O}\right)(\mathrm{py})_{2}\right]^{+}, \mathbf{4 \mathrm { H } ^ { + }}$, with $\mathrm{pKa}=4.5$ where the displaced carboxylate is dangling although functionally important since it is cis to the Ru-OH group.

Species 4 turns out to be a very robust catalyst with an impressive TOF $=8,000 \mathrm{~s}^{-1}$ at $\mathrm{pH}=7.0$ that is the best ever reported at this $\mathrm{pH}$ and about 3-4 orders of magnitude better than 
$\left[\mathrm{Ru}(\mathrm{bda})(\mathrm{pic})_{2}\right]$ at the same $\mathrm{pH}$, the best reported so far. The key for fast reactivity is mainly due to two factors: a) the easy access to high oxidation states, provided by the tda ${ }^{2-}$ ligand through the anionic nature of the carboxylate moieties and the capability of stabilizing a seven coordination to Ru in high oxidation states; and b) the functionality of the dangling carboxylate as a proton acceptor in an intramolecular fashion, while the incoming substrate water molecule undergoes a nucleophilic attack to the oxyl radical during the critical O-O bond formation step, as shown by our DFT calculations.

Supporting Information. Experimental details as well as additional spectroscopic, electrochemical and crystallographic results together with DFT data. This material is available free of charge via the Internet at http://pubs.acs.org.

\section{Acknowledgments}

R.M. thanks "La Caixa" foundation for a PhD grant. A.L. thanks MINECO (CTQ-2013-49075-R, SEV-2013-0319; CTQ-2014-52974-REDC) and "La Caixa" foundation for financial support. COST actions, CM1202 and CM1205 from the EU are also gratefully acknowledged. V.S.B. acknowledges supercomputer time from NERSC and financial support as part of the ArgonneNorthwestern Solar Energy 524 Research (ANSER) Center, an Energy Frontier Research Center funded by the U.S. Department of Energy, Office of 526 Science, Office of Basic Energy Sciences under Award Number 527 DE-SC0001059. The work at BNL (M.Z.E.) was carried out under contract DE-SC00112704 with the U.S. Department of Energy, Office of Science, Office of Basic Energy Sciences. We thank J. M. Martínez-Agudo from the Universidad de Valencia for his assistance with the EPR measurements. 


\section{REFERENCES:}

${ }^{1}$ Berardi, S.; Drouet, S.; Francàs, L.; Gimbert-Suriñach, C.; Guttentag, M.; Richmond, C.; Stoll, T.; Llobet, A. Chem. Soc. Rev. 2014, 43, 7501-7519.

2 Zeng, Q.; Lewis, F. W.; Harwood, L. M.; Hartl, F. Coord. Chem. Rev., 2015, in press.

${ }^{3}$ McCrory, C. C. L.; Jung, S.; Peters, J. C.; Jaramillo, T. F. J. Am. Chem. Soc. 2013, 135, 16977-16987.

${ }^{4}$ McCrory, C. C. L.; Jung, S.; Ferrer, I. M.; Chatman, S. M.; Peters, J. C.; Jaramillo, T. F. J. Am. Chem. Soc. 2015, 137, 4347-4357.

${ }^{5}$ Trotochaud, L.; Ranney, J. K.; Williams, K. N.; Boettcher, S. W. J. Am. Chem. Soc. 2012, 134, 1725317261.

${ }^{6}$ Smith, R. D. L.; Prévot, M. S.; Fagan, R. D.; Zhang, Z.; Sedach, P. A.; Siu, M. K. J.; Trudel, S.; Berlinguette, C. P. Science 2013, 340, 60-63.

${ }^{7}$ Matheu, R.; Francàs, L.; Chernev, P.; Ertem, M. Z.; Batista, V. S.; Haumann, M.; Sala, X.; Llobet, A. ACS Catal. 2015, 5, 3422-3429.

${ }^{8}$ Radaram, B.; Ivie, J. A.; Singh, W. M.; Grudzien, R. M.; Reibenspies, J. H.; Webster, C.E.; Zhao, X. Inorg. Chem. 2011, 50, 10564-10571.

${ }^{9}$ Reece, S. Y.; Hamel, J. A.; Sung, K.; Jarvi, T. D.; Esswein, A. J.; Pijpers, J. J. H.; Nocera, D. G. Science 2011, 334, 645-648.

${ }^{10}$ Mei, A.; Li, X.; Liu, L.; Ku, Z.; Liu, T.; Rong, Y.; Xu, M.; Hu, M.; Chen, J.; Yang, Y.; Grätzel, M.; Han, H. Science 2014, 345, 295-298.

${ }^{11}$ Sala, X.; Romero, I.; Rodríguez, M.; Escriche, L.; Llobet, A. Angew. Chem. Int. Ed. 2009, 48, 2842-2852.

${ }^{12}$ Romain, S.; Vigara, L.; Llobet, A. Acc. Chem. Res. 2009, 42, 1944-1953.

${ }^{13}$ Molecular Water Oxidation Catalysis: A Key Topic for New Sustainable Energy Conversion Schemes. Edited by A. Llobet. 2014 John Wiley and Sons Ltd. ISBN: 9781118413371

${ }^{14}$ Gersten, S. W.; Samuels, G. J.; Meyer, T. J. J. Am. Chem. Soc. 1982, 104, 4029-4030.

${ }^{15}$ Sens, C.; Romero, I.; Rodriguez, M.; Llobet, A.; Parella, T.; Benet-Buchholz, J. J. Am. Chem. Soc. 2004, 126, 7798-7799.

${ }^{16}$ Polyansky, D. E.; Muckerman, J. T.; Rochford, J.; Zong, R.; Thummel, R. P.; Fujita, E. J. Am. Chem. Soc. 2011, 133, 14649-14665.

${ }^{17}$ Concepcion, J. J.; Jurss, J. W.; Templeton, J. L.; Meyer, T. J. J. Am. Chem. Soc 2008, 130, 16462-16463.

${ }^{18}$ Hong, D.; Mandal, S.; Yamada, Y.; Lee, Y.-L.; Nam, W.; Llobet, A.; Fukuzumi, S. Inorg. Chem. 2013, 52, 9522-9531.

${ }^{19}$ Wang D., Ghirlanda G., Allen J. P. J. Am. Chem. Soc., 2014, 136, 10198-10201.

${ }^{20}$ Chen, G.; Chen, L.; Ng, S.-M.; Lau, T.-C. ChemSusChem 2014, 7, 127-134.

${ }^{21}$ Zhang, M.-T.; Chen, Z.; Kang, P.; Meyer, T. J., J. Am. Chem. Soc. 2013, 135, 2048-2051.

${ }^{22}$ Garrido-Barros, P.; Funes-Ardoiz, I.; Drouet, S.; Benet-Buchholz, J.; Maseras, F.; Llobet, A. J. Am. Chem. Soc. 2015, 137, 6758-6761.

${ }^{23}$ Sala, X.; Ertem, M. Z.; Vigara, L.; Todorova, T. K.; Chen, W.; Rocha, R. C.; Cramer, C. J.; Gagliardi, L.; Llobet, A. Angew. Chem. Int. Ed. 2010, 49, 7745-7747.

${ }^{24}$ Lianpeng Tong, L.; Duan, L.; Xu, Y.; Privalov, T.; Sun , L. Angew. Chem. Int. Ed. 2011, 50, 445-449.

${ }^{25}$ López, I.; Ertem, M. Z.; Maji, S.; Benet-Buchholz, J.; Keidel, A.; Kuhlmann, U.; Hildebrandt, P.; Cramer, C. J.; Batista, V. S.; Llobet, A. Angew. Chem. Int. Ed. 2014, 53, 205-209.

${ }^{26}$ Sala, X.; Maji, S.; Bofill, R.; Garcia-Anton, J.; Escriche, L.; Llobet, A., Acc. Chem. Res. 2014, 47, 504-516.

${ }^{27}$ Vigara, L.; Ertem, M. Z.; Planas, N.; Bozoglian, F.; Leidel, N.; Dau, H.; Haumann, M.; Gagliardi, L.; Cramer, C. J.; Llobet, A. Chem. Sci. 2012, 3, 2576-2586.

${ }^{28}$ Bozoglian, F.; Romain, S.; Ertem, M. Z.; Todorova, T. K.; Sens, C.; Mola, J.; Rodríguez, M.; Romero, I.; Benet-Buchholz, J.; Fontrodona, X.; Cramer, C. J.; Gagliardi, L.; Llobet, A. J. Am. Chem. Soc. 2009, 131, 15176-15187.

${ }^{29}$ Duan, L.; Bozoglian, F.; Mandal, S.; Stewart, B.; Privalov, T.; Llobet, A.; Sun, L. Nat. Chem. 2012, 4, 418423.

${ }^{30}$ Concepcion, J. J.; Tsai, M. K.; Muckerman, J. T.; Meyer, T. J. J. Am. Chem. Soc. 2010, 132, 1545-1557.

${ }^{31}$ Duan, L.; Fischer, A.; Xu, Y.; Sun, L. J. Am. Chem. Soc. 2009, 131, 10397-10399. 
${ }^{32}$ Richmond, C. J.; Matheu, R.; Poater, A.; Falivene, L.; Benet-Buchholz, J.; Sala, X.; Cavallo, L.; Llobet, A. Chem. Eur. J. 2014, 20, 17282-17286.

${ }^{33}$ Wang, L.; Duan, L.; Wang, Y.; Ahlquist, M. S. G.; Sun, L. Chem. Commun. 2014, 50, 12947-12950.

${ }^{34}$ Maji, S.; López, I.; Bozoglian, F.; Benet-Buchholz, J.; Llobet, A. Inorg. Chem. 2013, 52, 3591-3593.

${ }^{35}$ Privalov, T.; Åkermark, B.; Sun, L., Chem. Eur. J. 2011, 17, 8313-8317.

${ }^{36}$ Marelius, D. C.; Bhagan, S.; Charboneau, D. J.; Schroeder, K. M.; Kamdar, J. M.; McGettigan, A. R.;

Freeman, B. J.; Moore, C. E.; Rheingold, A. L.; Cooksy, A. L.; Smith, D. K.; Paul, J. J.; Papish, E. T.; Grotjahn, D. B. Eur. J. Inorg. Chem., 2014, 4, 676-689.

${ }^{37}$ Chen, Z.; Concepcion, J. J.; Hu, X.; Yang, W.; Hoertz, P. G.; Meyer, T. J. Proc. Natl. Acad. Sci. U.S.A. 2010, 107, 7225-7229.

${ }^{38}$ Song, N.; Concepcion, J. J.; Binstead, R. A.; Rudd, J. A.; Vannucci, A. K.; Dares, C. J.; Coggins, M. K.; Meyer, T. J. Proc. Natl. Acad. Sci. U.S.A. 2015, 112, 4935-4940.

${ }^{39}$ Galaup, C.; Couchet, J.-M.; Bedel, S.; Tisnès, P.; Picard, C. J. Org. Chem. 2005, 70, 2274-2284

${ }^{40}$ Planas, N.; Christian, G. J.; Roeser, S.; Mas-Marzá, E.; Kollipara, M. R.; Benet-Buchholz, J.; Maseras, F.; Llobet, A. Inorg. Chem. 2012, 5, 1889-1901.

${ }^{41}$ Planas, N.; Christian, G. J.; Mas-Marza, E.; Sala, X.; Fontrodona, X.; Maseras, F.; Llobet, A. Chem. Eur. J. 2010, 16, 7965-7968.

${ }^{42}$ Sander, A. C.; Maji, S.; Francas, L.; Böhnisch, T.; Dechert, S.; Llobet, A.; Meyer, F. ChemSusChem 2015, 8, 1697-1702.

${ }^{43}$ Pyykkö, P., J. Organomet. Chem. 2006, 691, 4336-4340.

${ }^{44}$ Zhao, Y.; Truhlar, D. G. J. Chem. Phys. 2006, 125, 194101

${ }^{45}$ Peverati, R.; Truhlar, D. G. J. Phys. Chem. Lett. 2012, 3, 117

${ }^{46}$ Roeser, S.; Farràs, P.; Bozoglian, F.; Martínez-Belmonte, M.; Benet-Buchholz, J.; Llobet, A. ChemSusChem 2011, 4, 153-153.

${ }^{47}$ Farras, P.; Maji, S.; Benet-Buchholz, J.; Llobet, A. Chem. Eur. J. 2013, 19, 7162-7172.

${ }^{48}$ Pearson, R. G. J. Am. Chem. Soc. 1963, 85, 3533-3539.

${ }^{49}$ Sens, C.; Rodriguez, M.; Romero, I.; Llobet, A.; Parella, T.; Sullivan, B. P.; Benet-Buchholz, J. Inorg. Chem. 2003, 42, 2040-2048.

${ }^{50}$ Francas, L.; Gonzalez-Gil, R. M.; Moyano, D.; Benet-Buchholz, J.; García-Antón, J.; Escriche, L.; Llobet, A.; Sala, X. Inorg. Chem. 2014, 53, 10394-10402.

${ }^{51}$ Wasylenko, D. W.; Ganesamoorthy, C.; Henderson, M.; Koivisto, B. D.; Osthoff, H.; Berlinguette, C. P. J. Am. Chem. Soc. 2010, 132, 16094-16106.

52 Costentin, C.; Drouet, S.; Robert, M.; Savéant, J.-M. J. Am. Chem. Soc. 2012, 134, 11235-11242.

${ }^{53}$ Costentin, C.; Savéant, J.-M. ChemElectroChem 2014, 1, 1226-1236.

${ }^{54}$ Rountree, E. S.; McCarthy, B. D.; Eisenhart, T. T.; Dempsey, J. L. Inorg. Chem. 2014, 53, 9983.

${ }^{55}$ Hirahara, M.; Ertem, M. Z.; Komi, M.; Yamazaki, H.; Cramer, C. J.; Yagi, M. Inorg. Chem., 2013, 52, 6354-6364.

${ }^{56}$ Angeles-Boza, A. M.; Ertem, M. Z.; Sarma, R.; Ibanez, C. H.; Maji, S.; Llobet, A.; Cramer, C. J.; Roth, J. P. Chem. Sci., 2014, 5, 1141-1152.

${ }^{57}$ Helm, L. M.; Stewart, M. P.; Bullock, R. M.; DuBois, M. R.; DuBois, D. L. Science, 2011, 333, 863-866 
Chart 1. Ligands used and discussed in this work with carbon atoms labeling for NMR assignment.
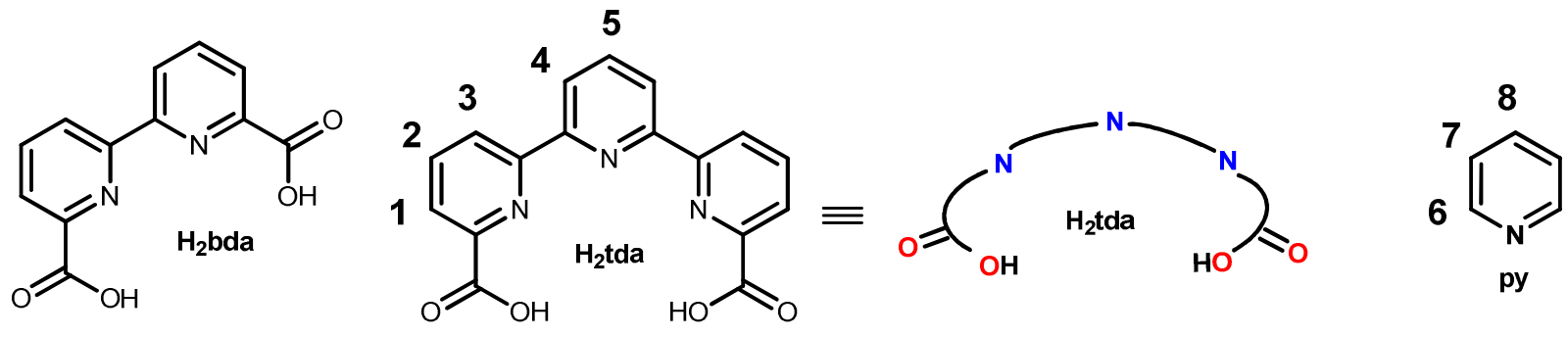


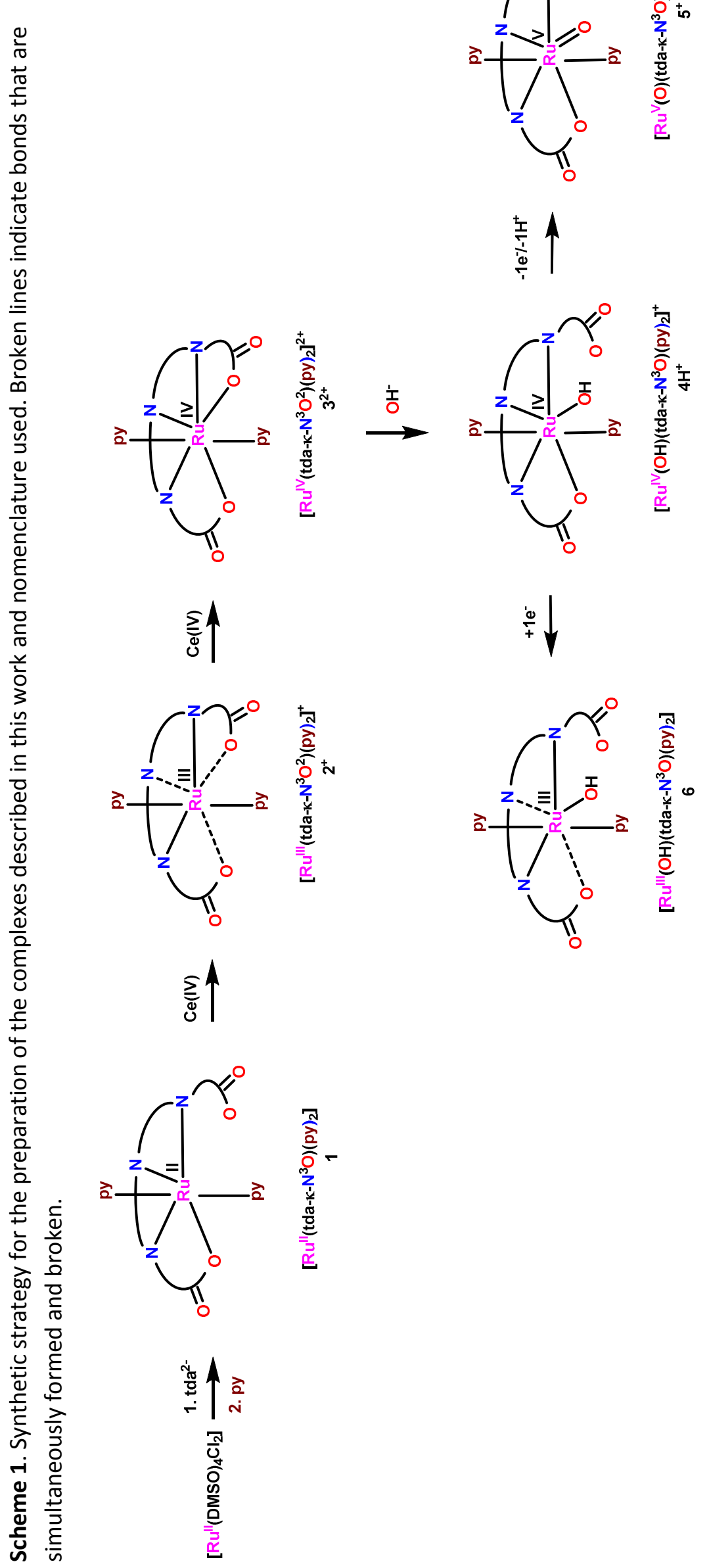




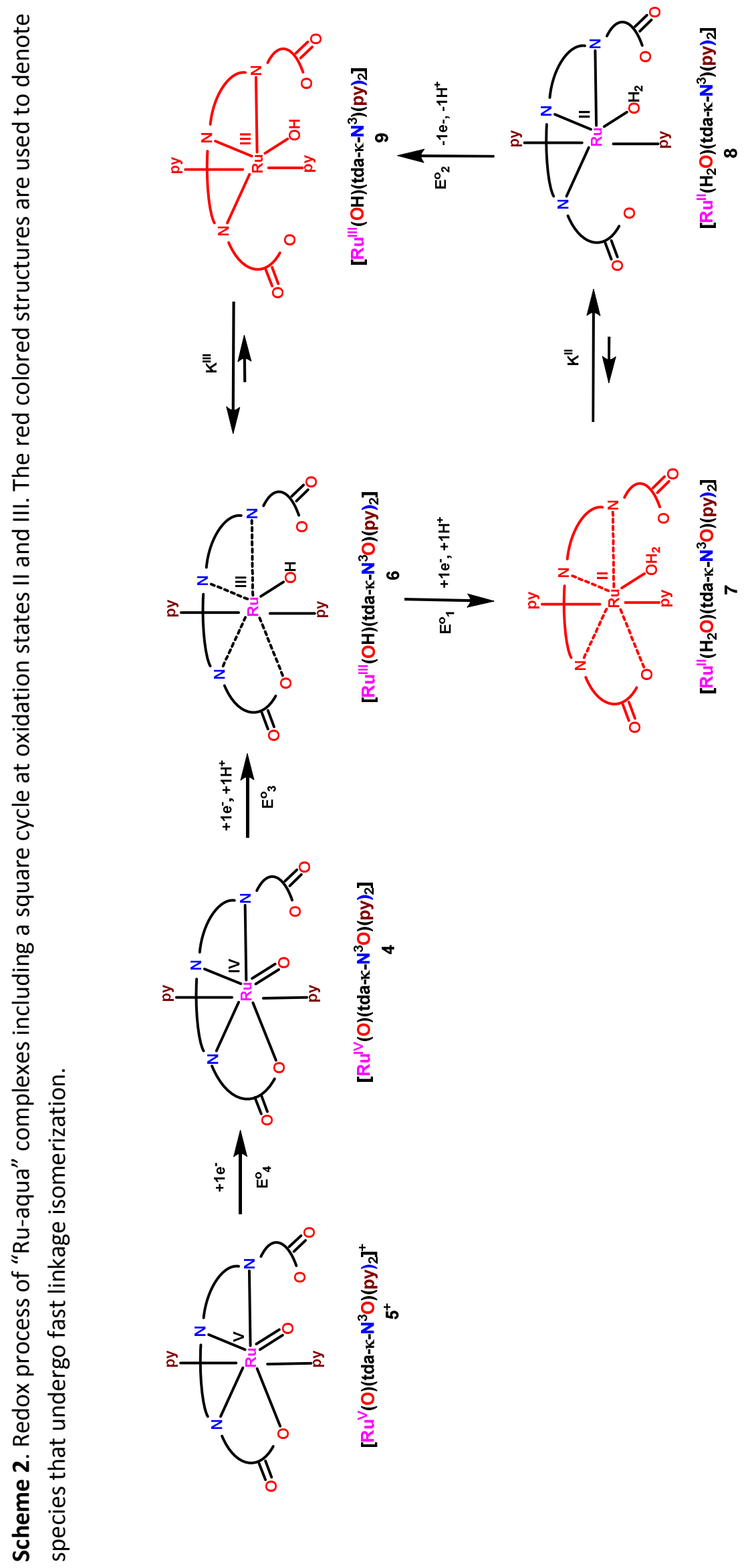




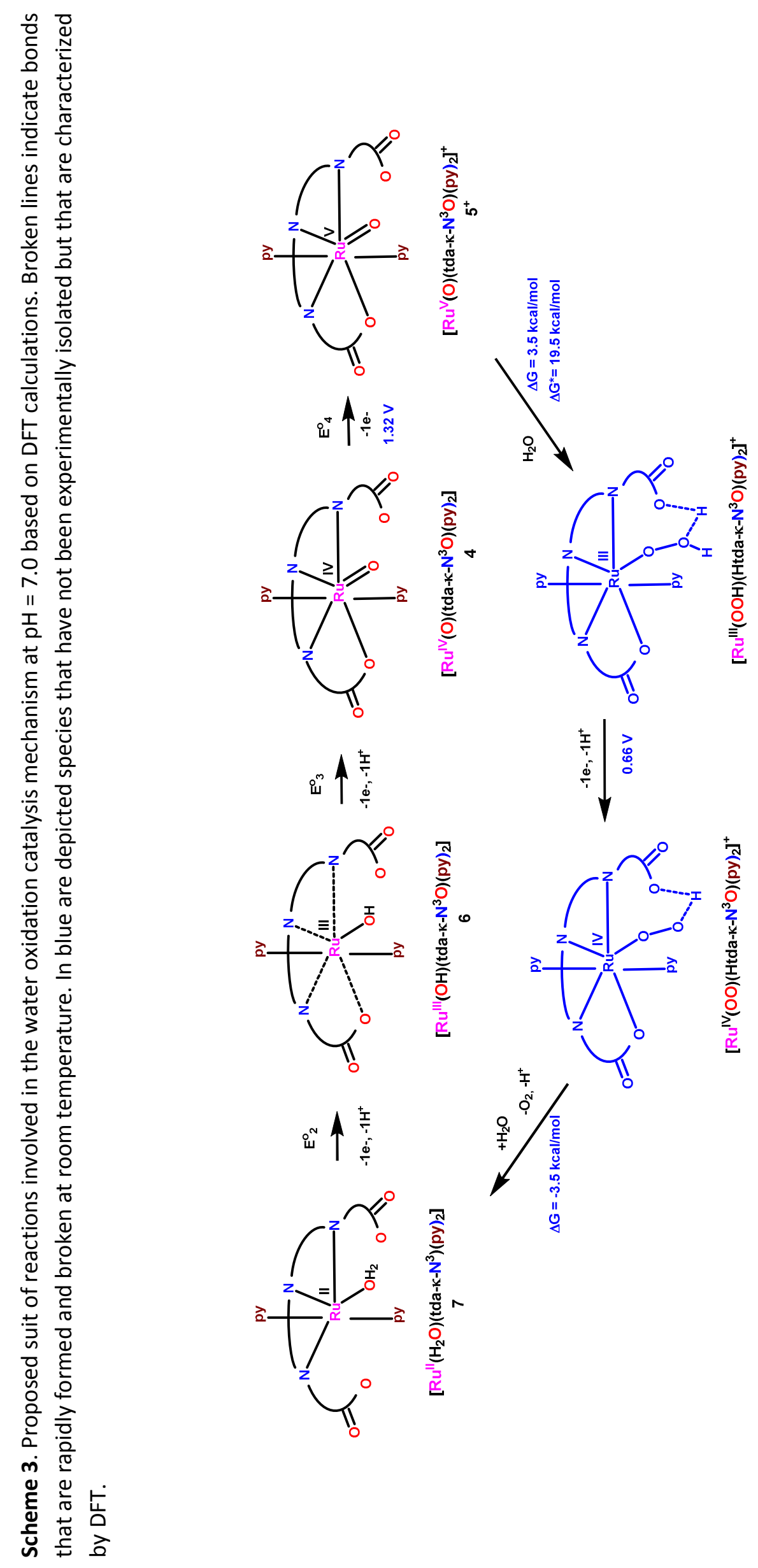




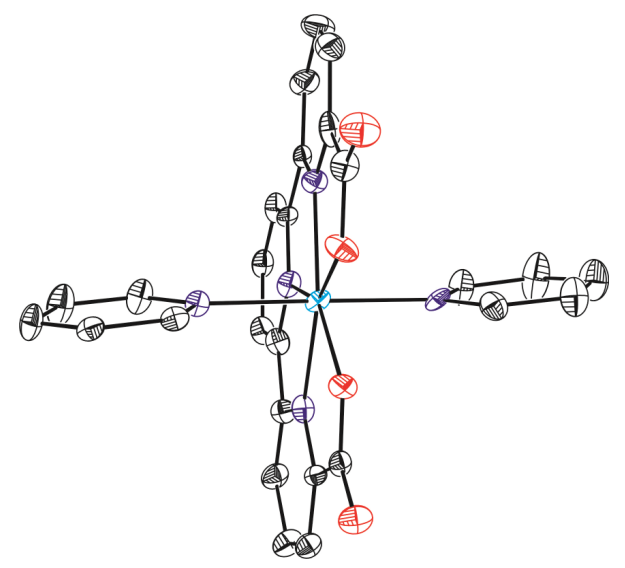

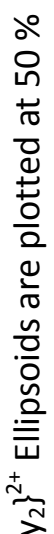
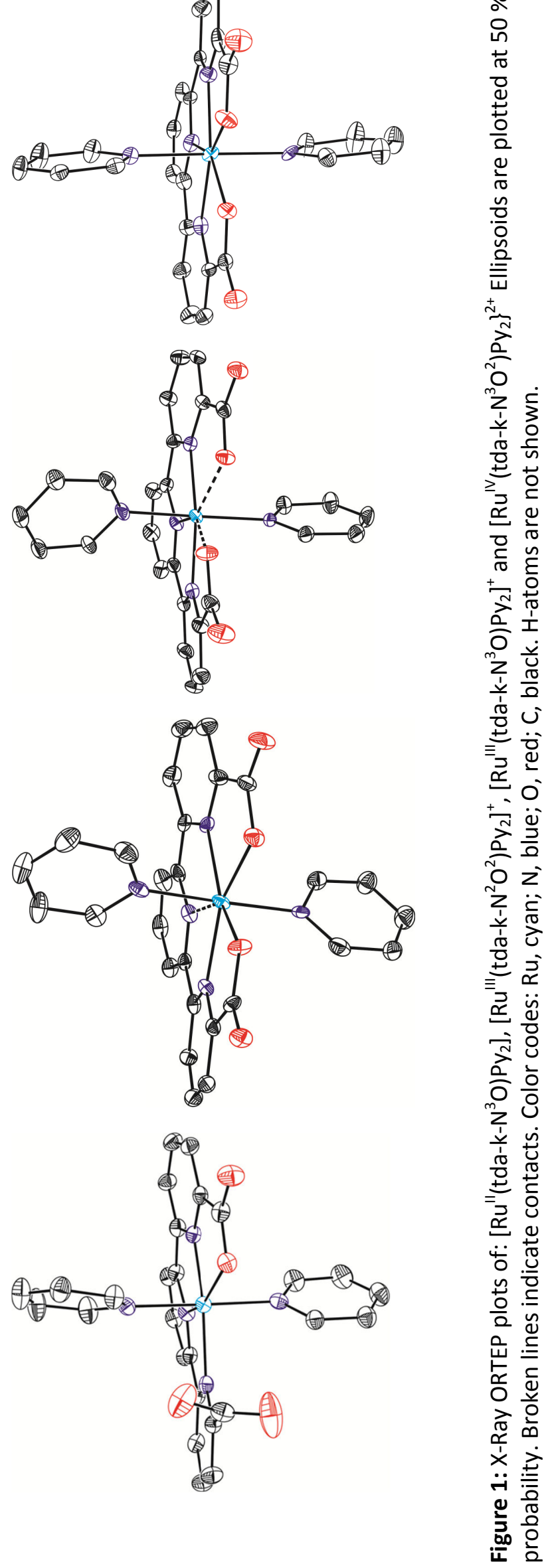


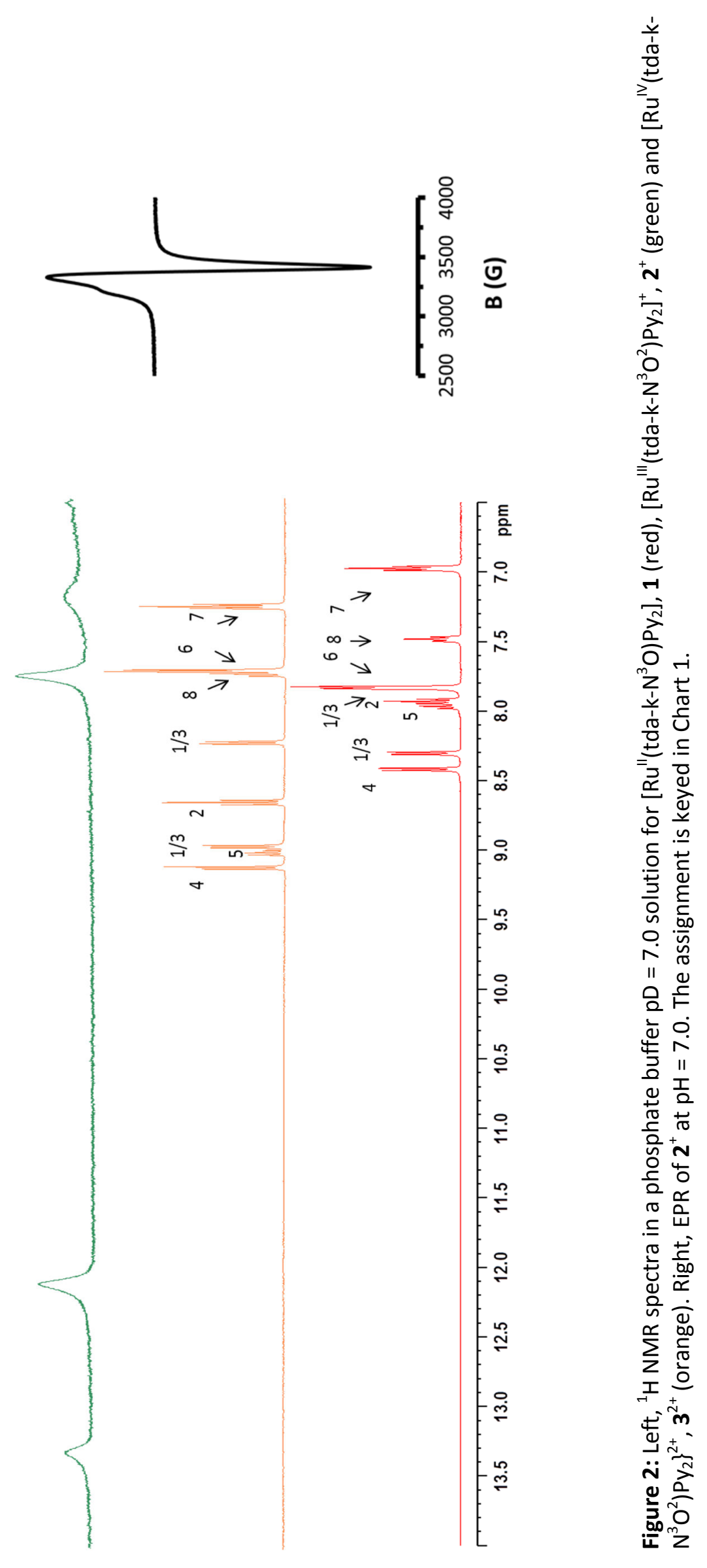




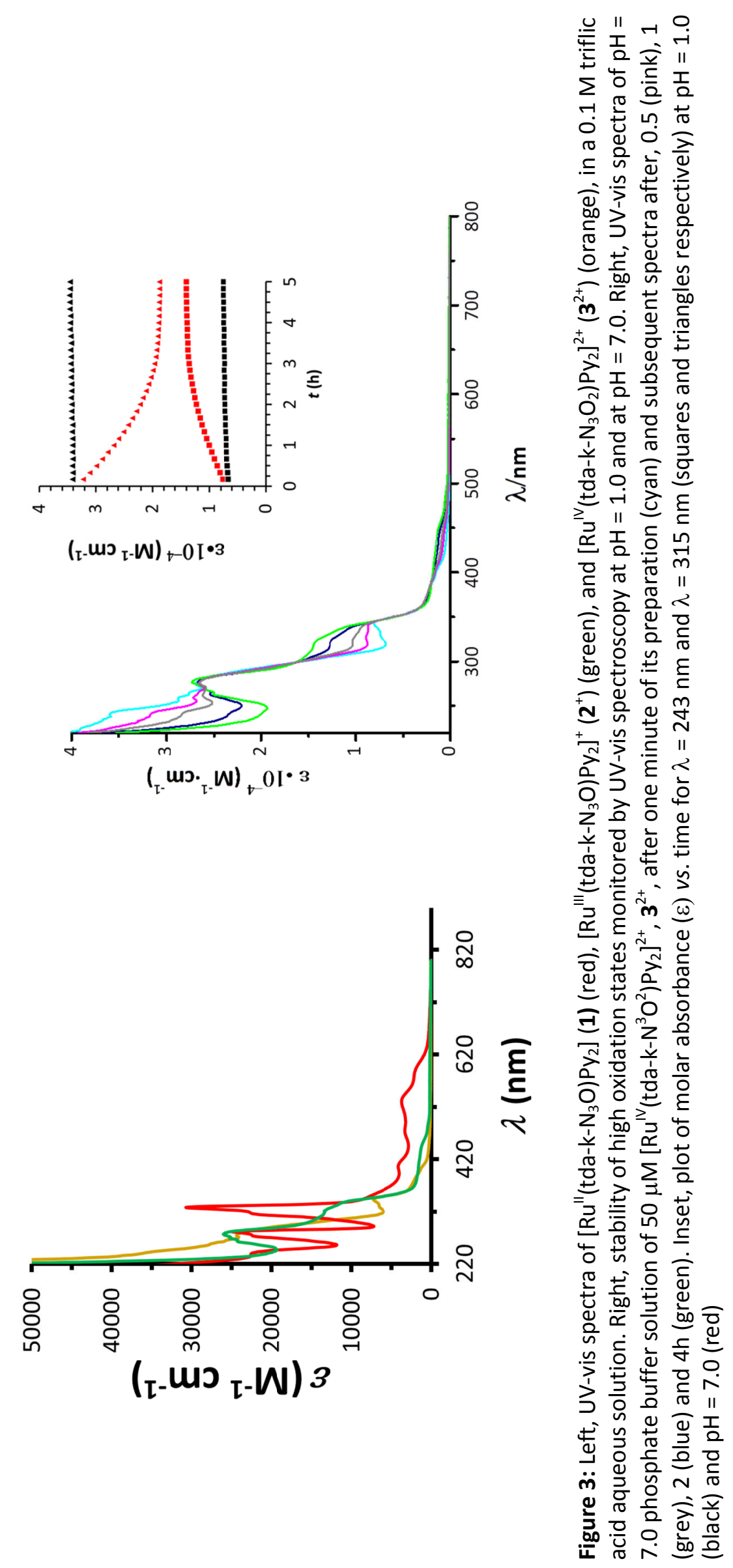




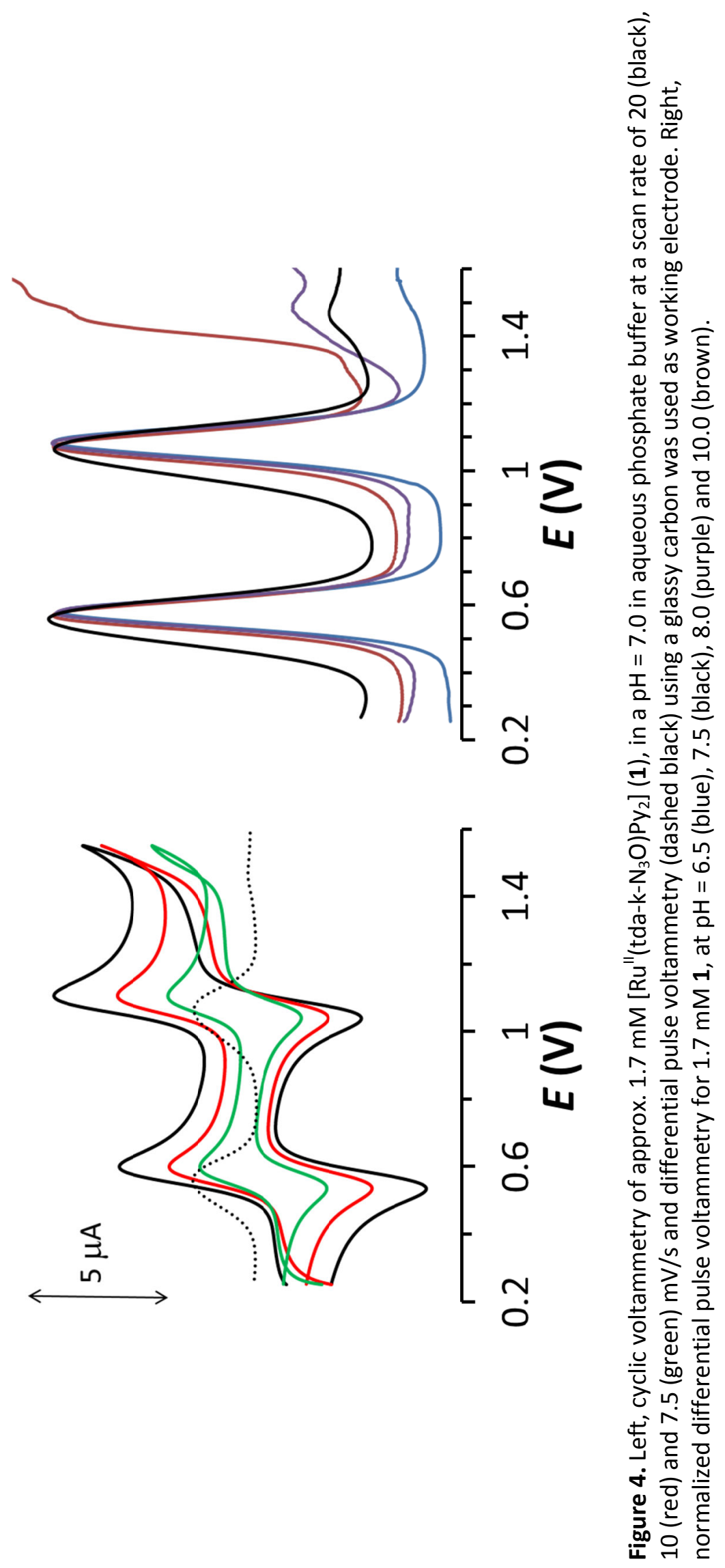




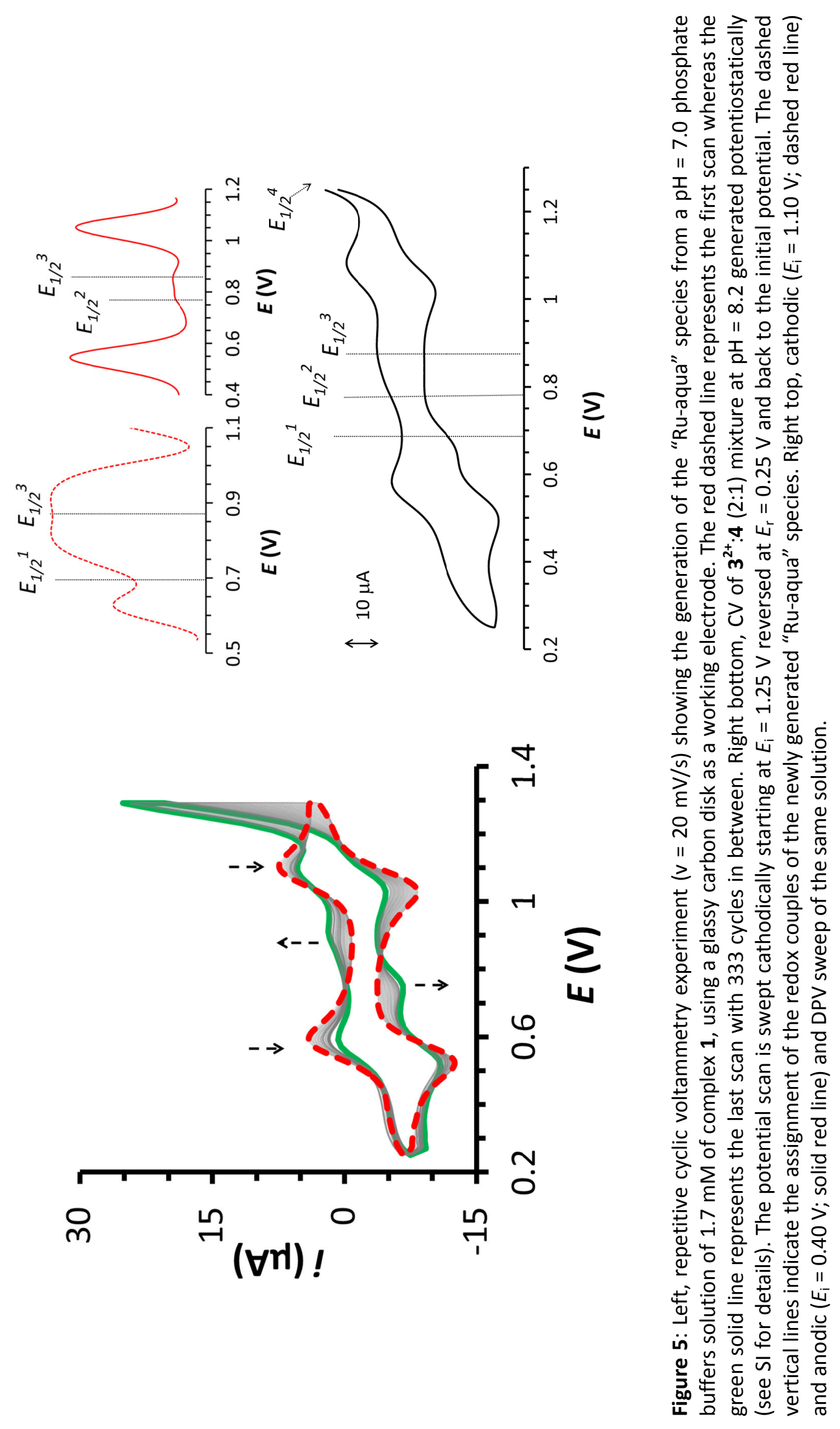



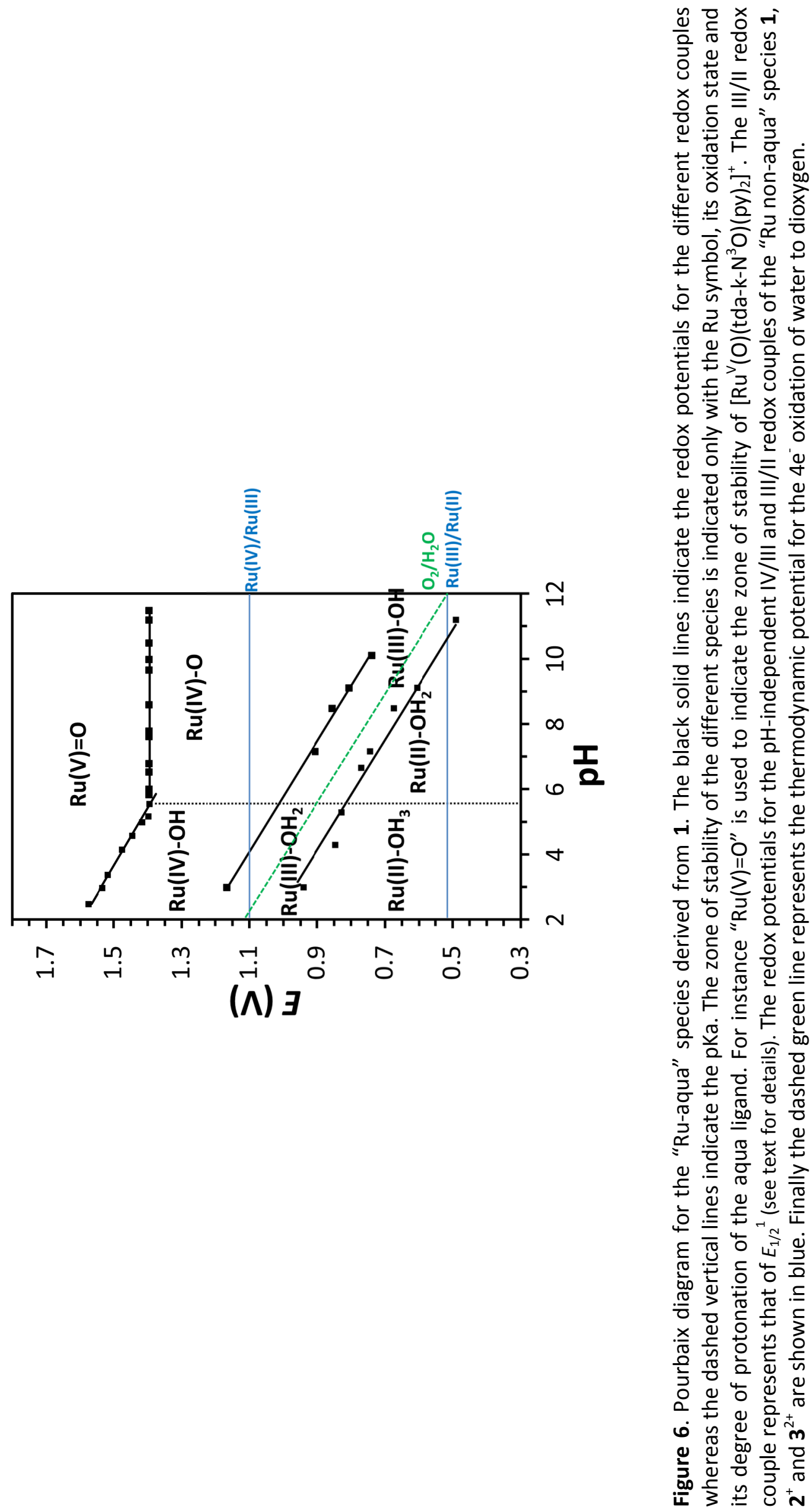


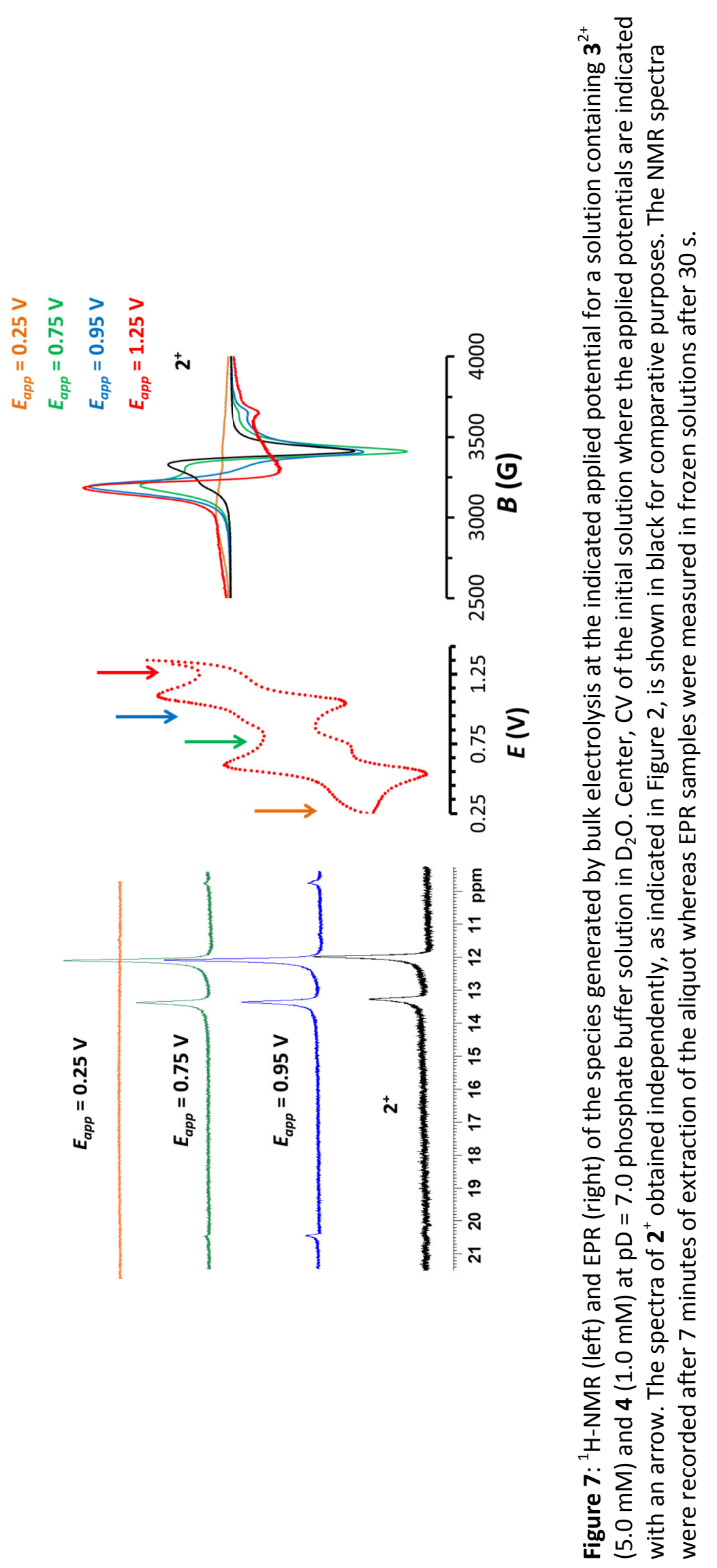




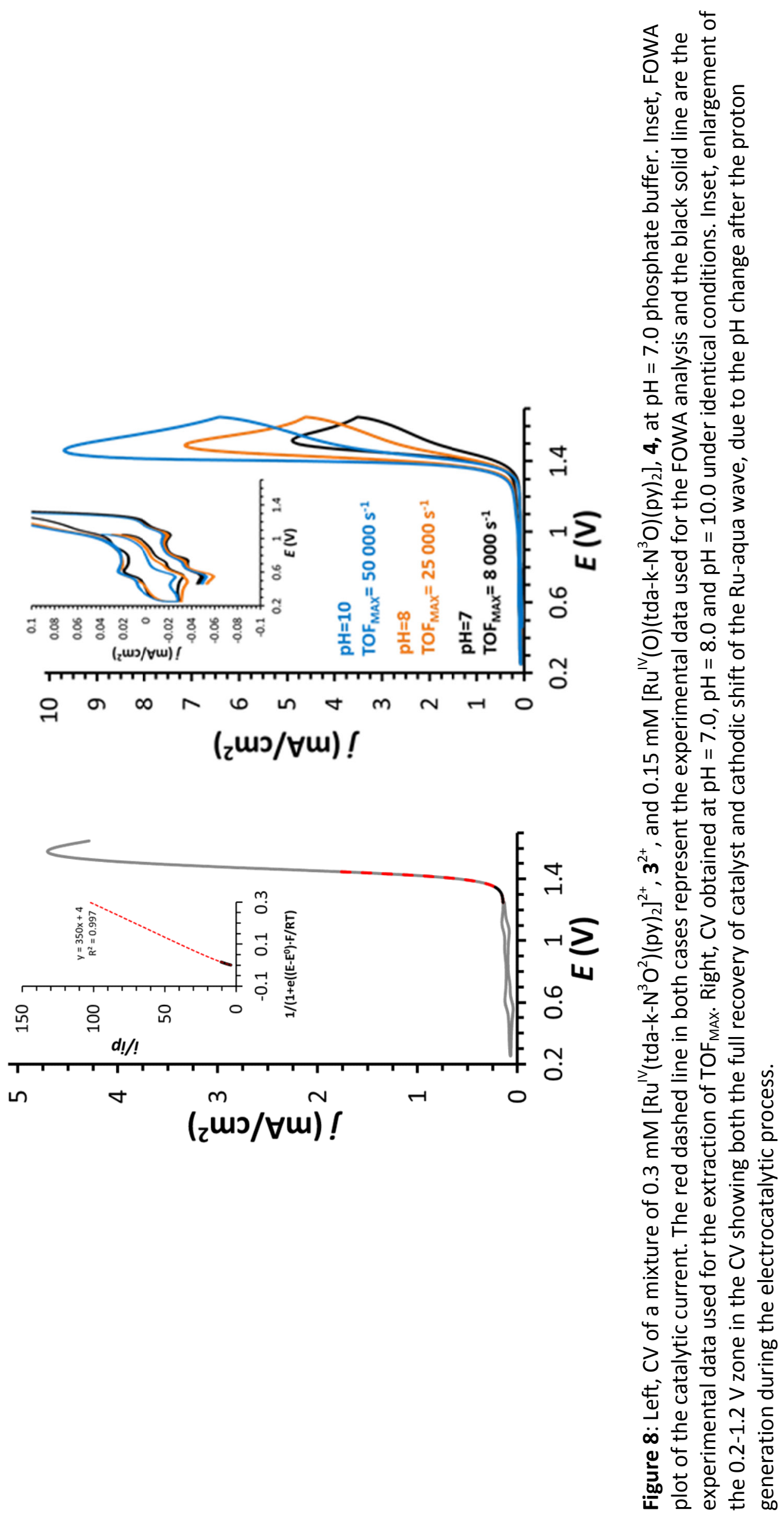




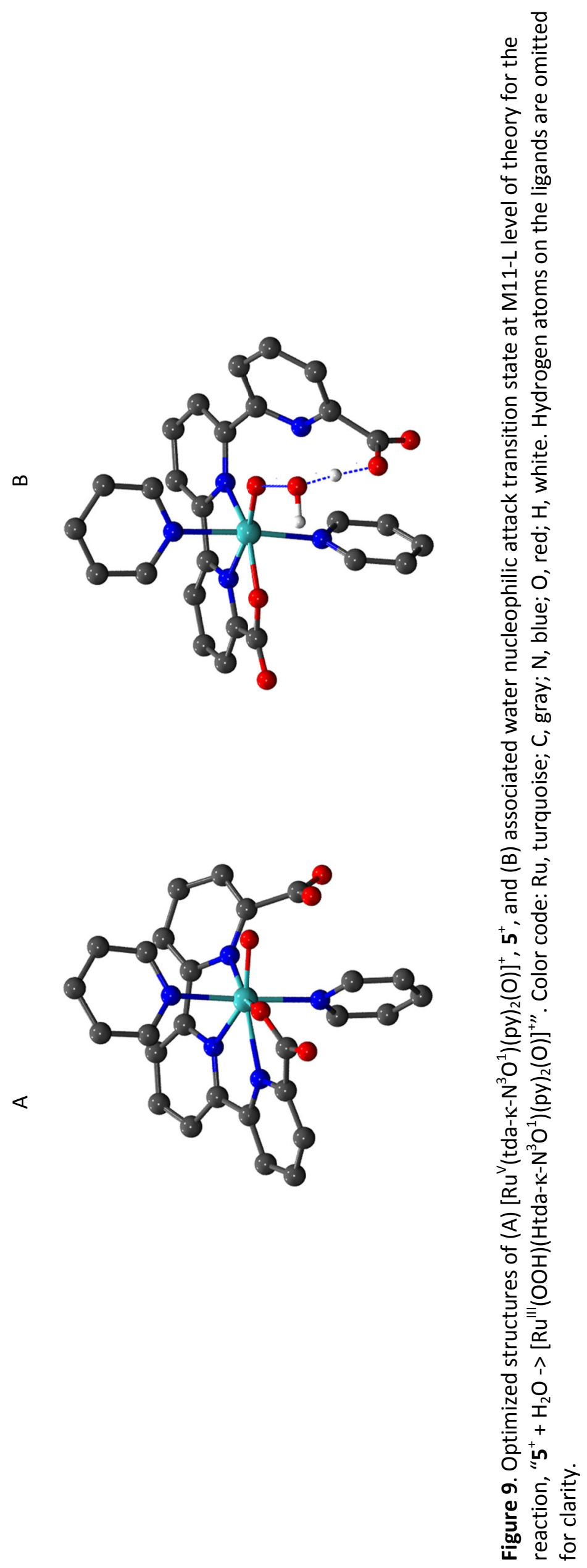




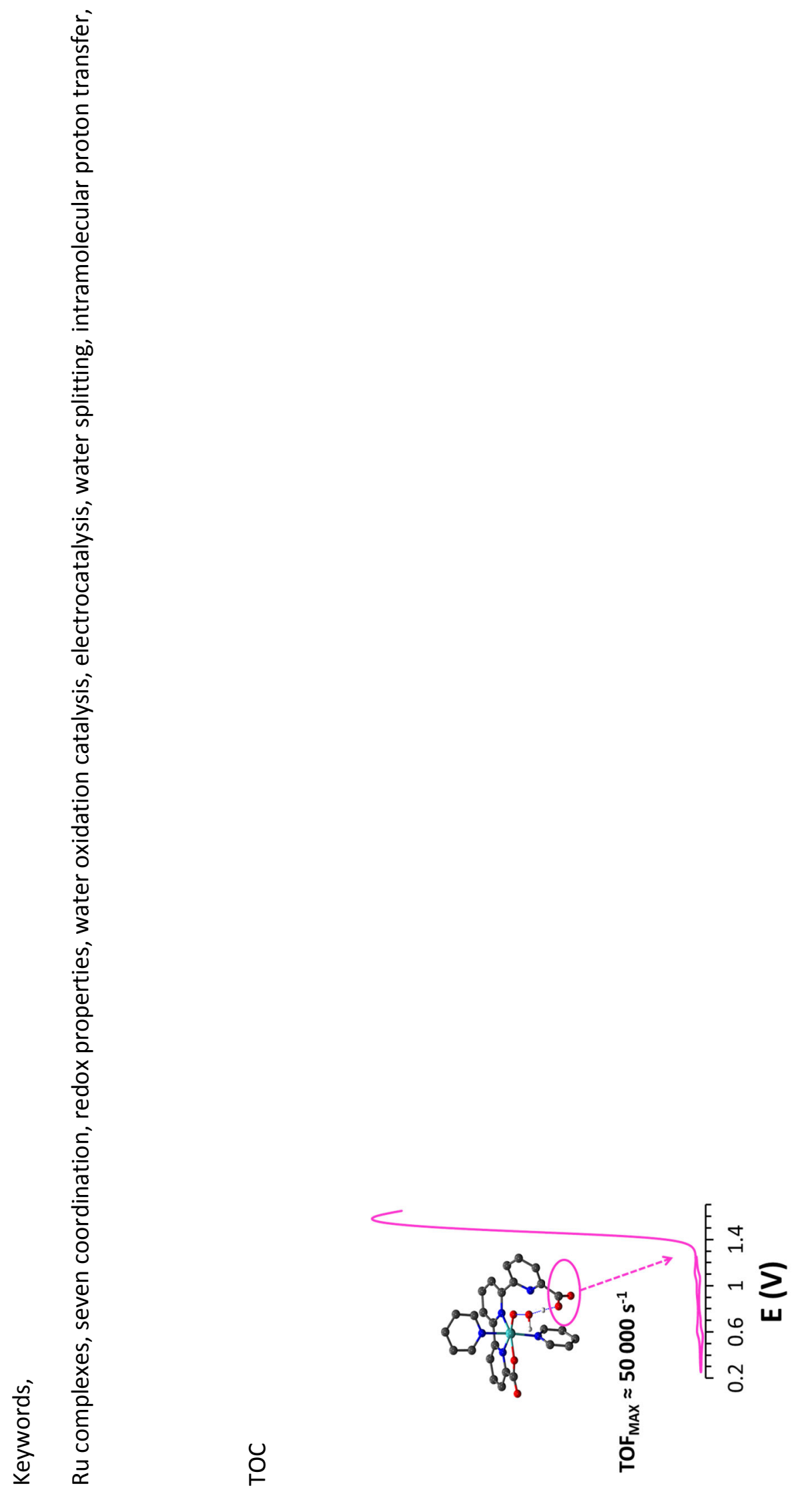

